\title{
Carbon Nanotube-Based Sensors
}

\author{
Niraj Sinha, Jiazhi Ma, and John T. W. Yeow* \\ Department of Systems Design Engineering, University of Waterloo, \\ 200 University Avenue (W), Waterloo, ON N2L 3G1, Canada
}

\begin{abstract}
Sensors continue to make significant impact in everyday life. There has been a strong demand for producing highly selective, sensitive, responsive, and cost effective sensors. As a result, research emphasis is on developing new sensing materials and technologies. Carbon nanotubes (CNTs) have many distinct properties that may be exploited to develop next generation of sensors. This manuscript reviews the distinct physical, electronic, and mechanical properties of CNTs. The main thrust of this review is to highlight the present and future research and development work in the area of carbon nanotube sensors for real-world applications. The technical challenges associated with CNT-based sensors, which remain to be fully addressed, have also been outlined at the end of the manuscript. This review aims to act as a reference source for researchers to help them in developing new applications of CNT-based sensors.
\end{abstract}

Keywords: Single-Walled Nanotubes, Multi-Walled Nanotubes, Carbon Nanotube Sensors, Sensor Applications.

\section{CONTENTS}

1. Introduction .

2. Synthesis and Purification of Carbon Nanotubes

2.1. Carbon Arc-Discharge Technique.

2. 2. Laser-Ablation Technique

2.3. Chemical Vapor Deposition (CVD) Technique .... 575

2.4. Purification $\ldots \ldots \ldots \ldots \ldots \ldots \ldots \ldots \ldots \ldots \ldots \ldots \ldots$

3. Properties of Carbon Nanotubes . . . . . . . . . . . . 577

4. Carbon Nanotube Based Sensors . . . . . . . . . .... 580

5. Applications of Carbon Nanotube Based Sensors . . . . . . . 583

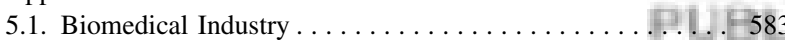

5.2. Automotive Industry $\ldots \ldots \ldots \ldots \ldots \ldots \ldots \ldots \ldots 84$

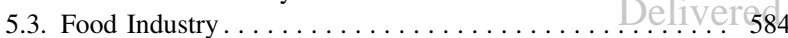

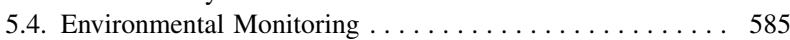

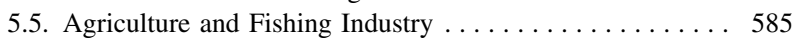

5.6. Manufacturing Industry $\ldots \ldots \ldots \ldots \ldots \ldots \ldots \ldots \ldots 6$

5.7. Security and Others .................... 586

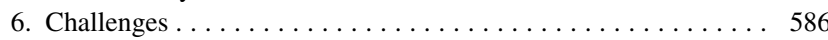

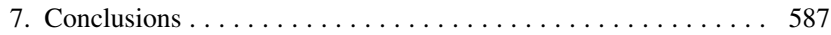

Acknowledgments . . . . . . . . . . . . . . . . . . . . 587

References and Notes ..................... 587

\section{INTRODUCTION}

Sensors are devices that detect or measure physical and chemical quantities such as temperature, pressure, sound, and concentration. The measurands are converted into an electrical signal. The main requirements of a good sensor are high sensitivity, fast response, low cost, high volume production, and high reliability. Sensors continue to make

\footnotetext{
${ }^{*}$ Author to whom correspondence should be addressed.
}

significant impact in everyday life with applications ranging from biomedical to automotive industry. This has led to intensive research activities across the world in developing new sensing materials and technologies. With the advent of nanotechnology, research is underway to create miniaturized sensors. Miniaturized sensors can lead to reduced weight, lower power consumption, and low cost. Materials such as inorganic semiconductors are used in making nanosensors. However, the discovery of carbon nanotubes (CNTs) has generated keen interest among researchers to develop CNT-based sensors for many applications. The application of CNTs in next-generation of sensors has the potential of revolutionizing the sensor industry due to their inherent properties such as small size, high strength, high electrical and thermal conductivity, and high specific surface area. ${ }^{1,2}$ CNTs are hexagonal networks of carbon atoms of approximately $1 \mathrm{~nm}$ diameter and 1 to 100 microns of length. They can essentially be thought of as a layer of graphite rolled-up into a cylinder. ${ }^{3}$ Depending on the arrangement of their graphene cylinders, there are two types of nanotubes: single-walled nanotubes (SWNTs) and multi-walled nanotubes (MWNTs). SWNTs have only one single layer of graphene cylinders; while MWNTs have many layers (approximately 50), as shown in Figure $1 .^{4}$ Furthermore, the films of synthesized CNTs can be aligned or random in nature.

Although the use of CNTs for sensing applications is promising, they are also associated with certain limitations. The objectives of this article are: (i) to describe the synthesis, purification, and properties of CNTs; (ii) to perform an 


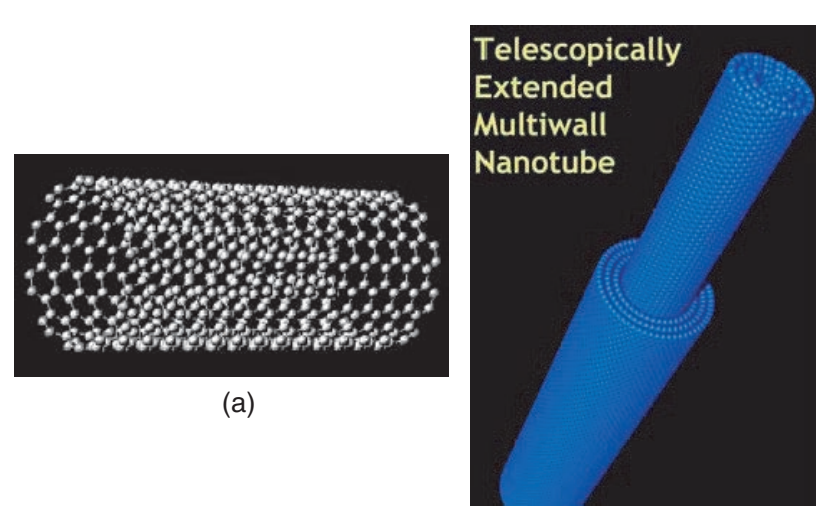

(b)

Fig. 1. (a) Structure of SWNTs. (b) Structure of MWNTs. Reprinted with permission from [4], http://www.lbl.gov. () Lawrence Berkeley National Laboratory.

extensive survey to highlight the areas where CNT-based sensors can be applied; (iii) to outline the potential challenges in commercializing CNT-based sensors; and (iv) to suggest possible research areas for addressing technical challenges associated with CNT-based devices.

\section{SYNTHESIS AND PURIFICATION OF CARBON NANOTUBES}

Generally, three techniques are being used for producing CNTs: (i) carbon arc-discharge technique, ${ }^{1,5-14}$ (ii) laserablation technique, ${ }^{15-22}$ and (iii) chemical vapor deposition (CVD) technique. ${ }^{23-37}$ In 1991, MWNTs were first discovered by Ijima by arc-discharge technique when he saw fine threads in a bit of shoot under electron microscope. ${ }^{1}$ The strands were very thin and long tubes of pure carbon. SWNTs were synthesized for the first time by Ijima and Ichihashi $^{7}$ and Bethune et al. ${ }^{8}$ in 1993 using metal catalyst in arc-discharge method. Laser-ablation technique was used by Thess et al. ${ }^{15}$ in 1996 to produce bundles of aligned SWNTs. For the first time, catalytic growth of MWNTs by CVD was proposed by Yacaman et al. ${ }^{23}$ The three techniques are discussed in detail below.

\subsection{Carbon Arc-Discharge Technique}

Two carbon electrodes are used in the carbon arc-discharge technique to generate an arc by DC current. The electrodes
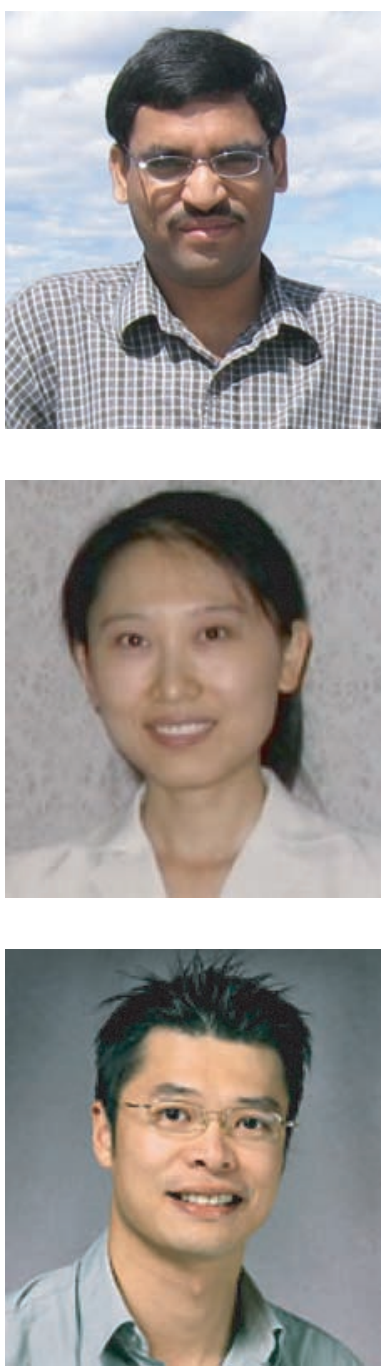

Niraj Sinha obtained a B.Tech. degree in manufacturing engineering from NIFFT, Ranchi, India, in 2000, and an M.Sc. degree in mechanical engineering from the University of Saskatchewan, Saskatoon, Canada, in 2004. He is currently pursuing his Ph.D. degree in the Department of Systems Design Engineering at University of Waterloo, Ontario, Canada. His current research interests are in the field of developing nanodevices using carbon nanotubes.

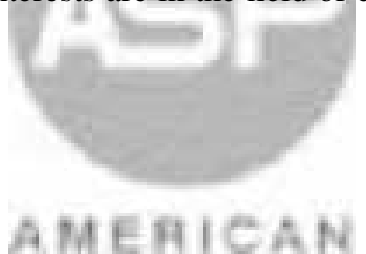

Jiazhi Ma received the B.Eng. and M.Eng. degrees in electrical and computer engineering from Tianjin University, Tianjin, China, in 2000 and 2003, respectively. She is currently pursuing the Ph.D. degree in the Department of Systems Design Engineering at the University of Waterloo, Waterloo, ON, Canada. Her current research interests are in the field of developing novel sensors and devices using nanotechnology for biomedical applications.

John T. W. Yeow received his B.A.Sc. in Electrical and Computer Engineering in 1997, M.A.Sc. and Ph.D. in Mechanical and Industrial Engineering in 1999 and 2003 respectively, all from the University of Toronto. He is a recipient of the Micralyn Microsystem Design Award in 2003, the NSERC Innovation Challenge Award in 2004, and the Douglas R. Colton Medal for Research Excellence in 2005. He is currently an Assistant Professor in the Department of Systems Design Engineering at the University of Waterloo. His research interests include microsystem and nanodevice design. 
are kept in a vacuum chamber and an inert gas is supplied to the chamber. The purpose of the inert gas is to increase the speed of carbon deposition. Initially, the two electrodes are kept independent. Once the pressure is stabilized, the power supply is turned on (about $20 \mathrm{~V}$ ) and the positive electrode is then gradually brought closer to the negative electrode to strike the electric arc. On arcing, the electrodes become red hot and a plasma forms. Once the arc stabilizes, the rods are kept about a millimeter apart while the CNT deposits on the negative electrode. The power supply is cut-off and the machine is left for cooling once a specific length is reached. The two most important parameters to be taken care of in this method are: (i) the control of arcing current and (ii) the optimal selection of inert gas pressure in the chamber. ${ }^{38}$

Arc-discharge technique produces high quality CNTs. While SWNTs can only be grown in presence of a catalyst, MWNTs do not need a catalyst for growth. MWNTs can be obtained by controlling the pressure of inert gas in the discharge chamber and the arcing current. The by-products are polyhedron shaped multi-layered graphitic particles in case of MWNTs. High quality MWNTs having diameters in the range of 2 to $20 \mathrm{~nm}$ and lengths of several microns at the gram level were synthesized for the first time by Ebbesen and Ajayan. ${ }^{6}$ A potential of approximately $18 \mathrm{~V}$ and a helium pressure of about 500 Torr was applied by them. Analysis by transmission electron microscopy (TEM) revealed that the nanotubes consisted of two or more carbon shells. The MWNTs produced by arc-discharge method were highly crystalline and were bound together by strong van der Waals forces. SWNTs with diameters $\sim 1 \mathrm{~nm}$ were synthesized by Ijima and Ichihashi ${ }^{7}$ using a gas mixture of 10 Torr methane and 40 Torr argon at a DC current of $200 \mathrm{~A}$ and a voltage of $20 \mathrm{~V}$. Bethune et al. ${ }^{8}$ experimented with $\mathrm{Co}, \mathrm{Ni}$, and $\mathrm{Fe}$ as catalysts to synthesize CNTs by using carbon as anode at currents between 95 to $105 \mathrm{~A}$ and He pressures between 100 to 500 Torr. The TEM analysis revealed that SWNTs of diameters $1.2 \pm 0.1 \mathrm{~nm}$ were obtained only with Co catalysts. Journet et al. ${ }^{12}$ optimized the SWNT growth by arc-discharge technique by using graphite cathode $(16 \mathrm{~mm}$ diameter, $40 \mathrm{~mm}$ long), graphite anode $(6 \mathrm{~mm}$ diameter, $100 \mathrm{~mm}$ long), mixture of catalysts ( $\mathrm{Ni}-\mathrm{Co}, \mathrm{Co}-\mathrm{Y}$, or $\mathrm{Ni}-\mathrm{Y}$ ), helium pressure of $660 \mathrm{~m} \mathrm{bar}$, arcing current of $100 \mathrm{~A}$, and voltage drop of $30 \mathrm{~V}$ between the electrodes. The deposited material consisted of high amount of entangled carbon ropes of diameters $5-20 \mathrm{~nm}$ as revealed by scanning electron microscopy (SEM). Li et al. ${ }^{13}$ used modified arc-discharge method, which used $\mathrm{FeS}$ as a promoter, to synthesize SWNTs. The diameters of CNT fibers obtained were 5 to $20 \mu \mathrm{m}$ and their length could reach up to $10 \mathrm{~cm}$. As evaluated by scanning electron microscopy, thermogravimetric analysis, and Raman spectroscopy, the synthesized SWNT fibers were $80 \%$ pure by volume. Recently, CNTs have been synthesized by arc-discharge in open air.
As this method does not require a controlled atmosphere, therefore, the cost of production may be reduced. ${ }^{14}$

\subsection{Laser-Ablation Technique}

In the laser-ablation technique for producing CNTs, intense laser pulses are utilized to ablate a carbon target. The pulsed laser-ablation of graphite in the presence of an inert gas and catalyst forms CNTs. ${ }^{15}$ The X-ray diffraction (XRD) and transmission electron microscopy revealed that the SWNTs produced by Thess et al. ${ }^{15}$ using laser-ablation were ropes (or bundles) of 5 to $20 \mathrm{~nm}$ diameter and tens to hundreds of microns of length. Arepalli et al. ${ }^{16}$ found that individual nanotubes of lengths tens of microns are formed in the vicinity of the target at the beginning. These nanotubes subsequently coalesce into bundles. Based on spectral emission and laser-induced fluorescence measurements, it was suggested by Scott et al. ${ }^{17}$ that the carbon for nanotube formation comes from direct ablation as well as from carbon particles suspended in the reaction zone. It was also proposed by them that the confinement of the nanotubes in the reaction zone within the laser beam allows the nanotubes to be purified and annealed during the formation process by laser heating. SWNTs and other nanotubular structures (graphite nanocages and low aspect ratio nanotubules) were synthesized by Braidy et al. ${ }^{18}$ by pulsed $\mathrm{KrF}$ laser-ablation of a graphite pellet at 500 Torr argon pressure, $1150{ }^{\circ} \mathrm{C}$ temperature, and a laser intensity of $8 \times 10^{8} \mathrm{~W} / \mathrm{cm}^{2}$. It was observed that relatively high UV laser intensity was detrimental to the growth of SWNTs. Takahashi et al. ${ }^{19}$ synthesized multi-layered MWNTs having tip angle of $15-20^{\circ}$ by using high vacuum laser-ablation. Graphite powder was dispersed on a $\mathrm{Si}$ (100) substrate and CNTs were grown selectively at high substrate temperature.

In general, some of the major parameters that determine the amount of CNTs produced are: the amount and type of catalysts, laser power and wavelength, temperature, pressure, type of inert gas present, and the fluid dynamics near the carbon target. ${ }^{39-41}$ When synthesizing SWNTs, the byproducts in case of arc-discharge and laser-ablation techniques are fullerenes, graphitic polyhedrons with enclosed metal particles, and amorphous carbon. ${ }^{40}$

\subsection{Chemical Vapor Deposition (CVD) Technique}

In the CVD technique, CNTs are synthesized by imparting energy to hydrocarbons. The imparted energy breaks the molecule into reactive radical species in the temperature range of $550-750{ }^{\circ} \mathrm{C}$. These reactive species then diffuse down to the substrate, which is heated and coated in a catalyst (usually a first row transition metal such as $\mathrm{Ni}, \mathrm{Fe}$, or Co) where it remains bonded. This result in the formation of CNTs. The commonly used hydrocarbon sources are methane, ethylene, and acetylene; while the commonly used energy sources are electron beam and resistive 
heating. Microtubules of up to $50 \mu \mathrm{m}$ length of CNTs were synthesized by Yacaman et al. ${ }^{23}$ by catalytic decomposition of acetylene over iron particles at $700{ }^{\circ} \mathrm{C}$. Li et al. ${ }^{24}$ used iron nanoparticles (embedded in mesoporous silica) as catalyst for large-scale synthesis of aligned CNTs. The tubes were $\sim 50 \mu \mathrm{m}$ long and well graphitized. A CVD technique using microwave energy for synthesizing MWNTs was developed by Varadan and Xie. ${ }^{27}$ They used acetylene as the hydrocarbon and cobalt as the catalyst at a temperature of $700{ }^{\circ} \mathrm{C}$. MWNTs prepared by this process had an average diameter of 20 to $30 \mathrm{~nm}$ and consisted of 26 layers. A sequential combination of radio frequency plasma enhanced CVD (RF PECVD) and thermal CVD was utilized by Park et al. ${ }^{28}$ CNTs were synthesized on stainless steel plates from acetylene and hydrogen gas mixture. Seidel et al. ${ }^{32}$ synthesized dense networks of SWNTs using Ni catalyst layers of $0.2 \mathrm{~nm}$ thickness by thermal CVD at temperatures as low as $600{ }^{\circ} \mathrm{C}$. Based on the interaction between the catalyst and its support; a growth model for CVD synthesis was proposed. According to them, the fast growth rates of SWNTs during CVD synthesis can only be explained by surface diffusion of hydrocarbons on the catalyst support or along the CNTs. Vohs et al. ${ }^{34}$ used metal $(\mathrm{Fe})$-encapsulated dendrimers as catalysts for low-temperature growth of CNTs. MWNTs were synthesized at $175{ }^{\circ} \mathrm{C}$ via decomposition of carbon tetrachloride in supercritical carbon dioxide by them. CVD technique with gas-phase catalyst delivery was used by Wei et al. ${ }^{35}$ to direct the assembly of carbon nanotubes in a variety of predetermined orientations, building them into one-, two-, and three-dimensional arrangements. This could be useful in the manufacture of electromechanical devices.

There are several parameters that affect the synthesis of CNTs by CVD technique. The key parameters are the nature of hydrocarbons, catalysts, and the growth temperature. Most of the CVD techniques utilize ethylene or acetylene as hydrocarbons for synthesizing MWNTs. It was observed by Chaisitsak et al. ${ }^{37}$ that both SWNTs and MWNTs can be synthesized by optimizing the catalyst. By optimizing the growth conditions, they synthesized SWNTs of diameter $0.65 \mathrm{~nm}$ at a substrate temperature of $660{ }^{\circ} \mathrm{C}$. With regards to the effect of temperature, the density and growth rate of CNTs increase with an increase in temperature. Also, the CNTs tend to be vertically aligned as the temperature increases. Taguchi analytical model has been applied by Maheshwar et al. ${ }^{42}$ to optimize the effective parameters of CVD for controlling the production of CNTs. Quantitative contributions of process parameters as well as optimum factor levels have been obtained by them using analysis of variance (ANOVA) and analysis of mean (AOM) respectively. Although excellent alignment and positional control on the nanometer scale can be achieved with the CVD technique, there are high defect densities in the MWNT structures grown by this process.
It is most likely due to the lack of sufficient thermal energy for annealing CNTs because of relatively low growth temperature. ${ }^{40}$

A comparison among these three CNT synthesis techniques indicates that arc-discharge and laser-ablation methods produce high yields $(>70 \%)$ of SWNTs, and the cost of producing CNTs by arc-discharge method is cheaper. However, the main disadvantages with these processes are: (i) tangled CNTs are synthesized that make the purification and applications of CNTs difficult; and (ii) these processes rely on evaporation of carbon atoms at temperatures $>3000{ }^{\circ} \mathrm{C}^{43}$ In addition to materials scale-up, CVD technique offers controlled synthesis of aligned and ordered CNTs. ${ }^{44,45}$ Although the microstructure of the CNT tips synthesized by CVD technique have well-formed caps compared to other techniques, they often have interrupted graphite layers. In applications such as scanning probe microscopy, tips are very important. Although CVD process appears technologically easier, the required quality of tips can be made by arc-discharge method. ${ }^{46}$

\subsection{Purification}

In all the above mentioned preparation methods, the nanotubes come with a number of impurities, which depend on the technique used. The purity of CNTs can be evaluated qualitatively using Raman spectroscopy, ${ }^{47}$ while near infrared spectroscopy can be used for the quantitative assessment. ${ }^{48}$ The most common impurities are carbonaceous materials, whereas metals are the other types of impurities generally observed. ${ }^{38}$ The impurities can be purified by oxidation in the carbon arc-discharge technique as the carbonaceous impurities have high oxidation rates. However, when $95 \%$ of the starting materials are oxidized, only 10 to $20 \%$ of the remaining material comprises pure nanotubes. ${ }^{49}$ For purification by oxidation, generally two approaches are followed: (i) gas phase purification ${ }^{49,50}$ and (ii) liquid phase purification. ${ }^{51-53}$ Low yield of purification by gas phase oxidation was observed by Ebbesen et al. ${ }^{49}$ Therefore, Hiura et al. $^{51}$ attempted liquid phase oxidation for more homogeneous oxidation. Kim et al. ${ }^{53}$ used nitric acid, sulphuric acid, and their mixture as oxidants. As observed by scanning electron microscopy (SEM), purified SWNTs of length less than $2 \mu \mathrm{m}$ were obtained. TEM confirmed that the SWNTs were purified with little damage on the surface and metal catalysts were efficiently removed. The size distribution was characterized by them with field-flow fractionation (FFF) method. A purification technique for SWNTs that are synthesized by pulsed laser-ablation technique was proposed by Bandow et al. ${ }^{54}$ They used a cationic surfactant and trapped SWNTs on a membrane filter. $90 \%$ purity by weight after purification was observed by them. However, the technique was microscale in nature and was not found very useful for purifying large batches. A macroscale technique was proposed by Rinzler et al. ${ }^{55}$ to overcome this limitation. The 
purification process proposed by them can be scaled to industrial levels of throughput when such volumes of SWNT material become available. For the SWNTs grown by CVD of carbon monoxide, a purification process has been developed by $\mathrm{Xu}$ et al., ${ }^{56}$ which consisted of sonication, oxidation, and acid washing. MWNTs grown by CVD technique were subjected to wet and dry oxidation by Biro et al. ${ }^{57}$ to remove impurities and traces of catalysts. It was observed that the $\mathrm{KMnO}_{4} / \mathrm{H}_{2} \mathrm{SO}_{4}$ aqueous oxidation procedure was effective in reducing the Co catalyst while moderately damaging the outer wall of CNTs.

Some other techniques have also been used to purify CNTs. CNTs were boiled in nitric acid aqueous solutions by Dujardin et al. ${ }^{58}$ to remove amorphous carbon and metal particles. SWNTs with more than $90 \%$ purity were generated by Shelimov et al. ${ }^{59}$ using ultrasonically assisted microfiltration from amorphous and crystalline carbon impurities and metal particles. A scalable purification method for SWNTs was developed by Harutyunyan et al. ${ }^{60}$ using microwave heating in air followed by treatment with hydrochloric acid. Microwave-assisted purification has been used by Ko et al. ${ }^{61}$ for purification of MWNTs. Raman spectroscopy and thermogravimetric analysis revealed that a temperature of $180{ }^{\circ} \mathrm{C}$ was suitable for the purification of CNTs. It was observed that purification temperatures above $180{ }^{\circ} \mathrm{C}$ decomposed the nanotubes, while temperatures below $180{ }^{\circ} \mathrm{C}$ were not effective in removing impurities. A protocol for the characterization of SWNTs' material quality has been proposed by Arepalli et al. ${ }^{62}$ It consumes less than $30 \mathrm{mg}$ of material and the amount of residual metal catalyst is determined directly. Numerical measures have been established by them for parameters (such as homogeneity and thermal stability) for easy comparison of SWNT materials.

However, all the purification methods change the structural surfaces of CNTs. This may result in change in the electrical and mechanical properties of purified nanotubes. Therefore, the main thrust of the research should be in the area of producing purified CNTs in a single-step process to conserve the fascinating features of CNTs.

\section{PROPERTIES OF CARBON NANOTUBES}

As the applications of CNTs are related to some of their specific properties, an overview of their properties is very important before exploring their potential applications. For example, CNTs can be used as filters for filtration of bacterial contaminants such as Escherichia coli from water and heavy hydrocarbons from petroleum because of their exceptional thermal and mechanical stability and high surface area. ${ }^{63}$ Although SWNTs are structurally similar to a single layer of graphite (that is a semiconductor with zero band gap), they can be either metallic or semiconducting depending upon the tube diameter and the chirality (the sheet direction in which the graphite sheet is rolled to form
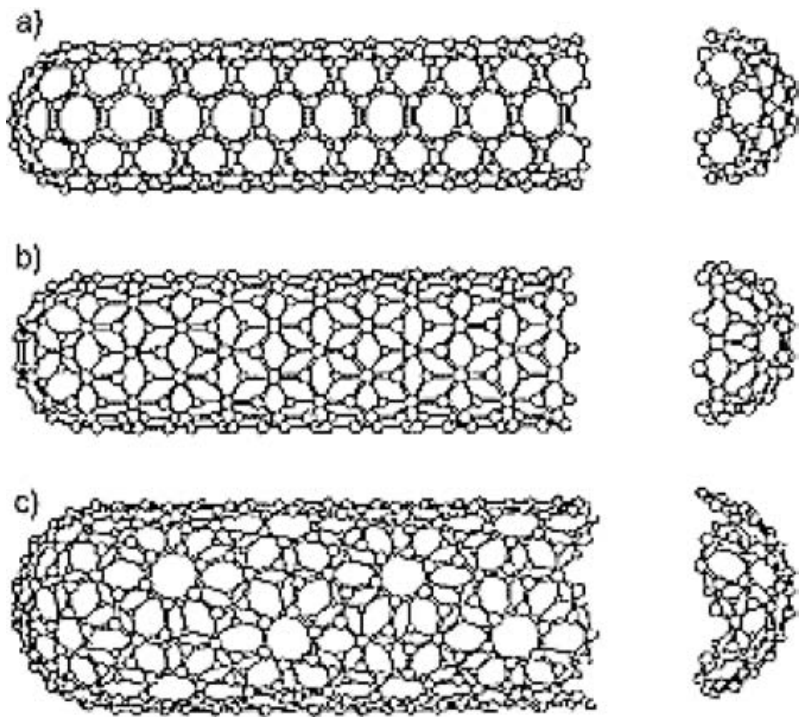

Fig. 2. Armchair, zigzag, and chiral nanotubes. Reprinted with permission from [3], M. S. Dresselhaus et al., Science of Fullerenes and Carbon Nanotubes, Academic Press, New York (1996). (C) 1996, Elsevier.

$200616: 40: 57$

a nanotube cylinder). ${ }^{64,65}$ The diameter $(d)$ and the chiral angle $(\theta)$ can be obtained by an integer pair $(n, m)$ using Eqs. (1) and (2). ${ }^{66}$

$$
\begin{gathered}
d=\frac{a \sqrt{m^{2}+m n+n^{2}}}{\pi} \\
\theta=\arctan \left[-\frac{\sqrt{3} n}{2 m+n}\right]
\end{gathered}
$$

where $a$ is the lattice constant in the graphite sheet.

The relation between $n$ and $m$ defines three categories of CNTs: (i) armchair $\left(n=m\right.$ and chiral angle equal to $\left.30^{\circ}\right)$; (ii) zigzag ( $n=0$ or $m=0$ and chiral angle $=0^{\circ}$ ); and (iii) chiral (other values of $n$ and $m$ and chiral angles between $0^{\circ}$ and $\left.30^{\circ}\right) \cdot{ }^{67}$ Figure 2 shows all the three categories of CNTs. ${ }^{3}$ All armchair nanotubes are metals, as well as those with $n-m=3 j$ ( $j$ being a nonzero integer). All others are semiconductors, which have the band gap that is inversely related to the diameters of the nanotubes. ${ }^{68}$ MWNTs are either nested CNT shells ${ }^{69}$ or have cinnamon roll like structure. ${ }^{70}$ For the development of molecular electronics, methods have been proposed by Banerjee et al. ${ }^{71}$ to separate metallic and semiconducting SWNTs.

The dielectric responses of the carbon nanotubes are found to be highly anisotropic. Owing to their nearly one dimensional electronic structure, the electronic transport in metallic SWNTs and MWNTs occurs ballistically (without scattering) over long lengths. This enables nanotubes to carry high currents with negligible heating. ${ }^{72,73}$ It was observed through experiments by Wei et al. ${ }^{74}$ that MWNTs can carry high current densities up to $10^{9}-10^{10} \mathrm{~A} / \mathrm{cm}^{2}$ and can conduct current without any measurable change in their resistance or morphology for extended periods of time at temperature up to $250{ }^{\circ} \mathrm{C}$. This points to the 
potential of CNTs as interconnects in large-scale integrated nanoelectronic devices. In another study, Koratkar et al. ${ }^{75}$ found that the temperature sensitivity of vertically aligned MWNT films was independent of heating/cooling rates and without hysteresis. It was conceived from the results that miniaturized temperature sensors can be designed using such aligned MWNT films. However, gas adsorption and collisions affect the electrical transport in SWNTs. The effects of gas adsorption and collisions on the thermoelectric power and resistivity of mats of tangled SWNT bundles were studied by Sumanasekera et al. ${ }^{76}$ They found that the degassed metallic SWNTs in a bundle are $n$ type. It was also observed that the gas collisions with the nanotube wall increase thermoelectric power and resistivity.

The electrical and electronic properties of nanotubes are affected by distortions like bending and twisting. Pentagon-heptagon pair is introduced in CNTs by bending, which results in metal-metal and semiconductormetal nanoscale junctions that can be used for nanoswitches. ${ }^{77,78}$ The effect of bending becomes important when bending angles are more than $45^{\circ}$. At this stage, kinks appear in the structure of the tube, resulting in the reduction in conductivity of CNTs. ${ }^{79}$ However, the presence of a metal nanowire inside the nanotube greatly suppresses the tube-buckling instability. In this case, increased tube diameter leads to an increase in the bending strength. ${ }^{80} \mathrm{~A}$ model has been developed by Wang et al. ${ }^{8}$ to study the elastic buckling of individual MWNTs under radial pressure. The critical pressure predicted by the model has been found in good agreement with the experimental results. A band gap opens upon twisting, which turns metallic CNTs to semiconducting. CNT structures collapse when twisted above a certain angle. ${ }^{82}$ Also, superconductivity in SWNTs has been observed but only at low temperatures. ${ }^{83}$ Doping of CNTs provide various possibilities for controlling their physical properties. Doped CNTs can find applications in nanoelectronics, spintronics, field emission, nonlinear optics, and chemical sensors. ${ }^{84}$ CNTs align themselves along field lines under high electric fields, as shown in Figure 3. The relative magnitude of the field responsible for polarization and directed motion has been found to be dependent on the morphology of the nanotubes used. These observations may lead to novel electromechanical applications for CNTs. ${ }^{85}$

Mechanically, CNTs are currently the strongest known fibers because the carbon-carbon bond observed in graphite is one of the strongest in nature. Elastic properties of CNTs can be obtained from experiment by assuming them structural members. The Young's modulus (a measure of stiffness) of individual MWNTs was first determined by Treacy et al. ${ }^{86}$ They estimated the Young's modulus of isolated CNTs by measuring the amplitude of their intrinsic thermal vibrations in the transmission electron microscope (TEM). The average value of Young's modulus was found to be $1800 \mathrm{GPa}$. However, the technique
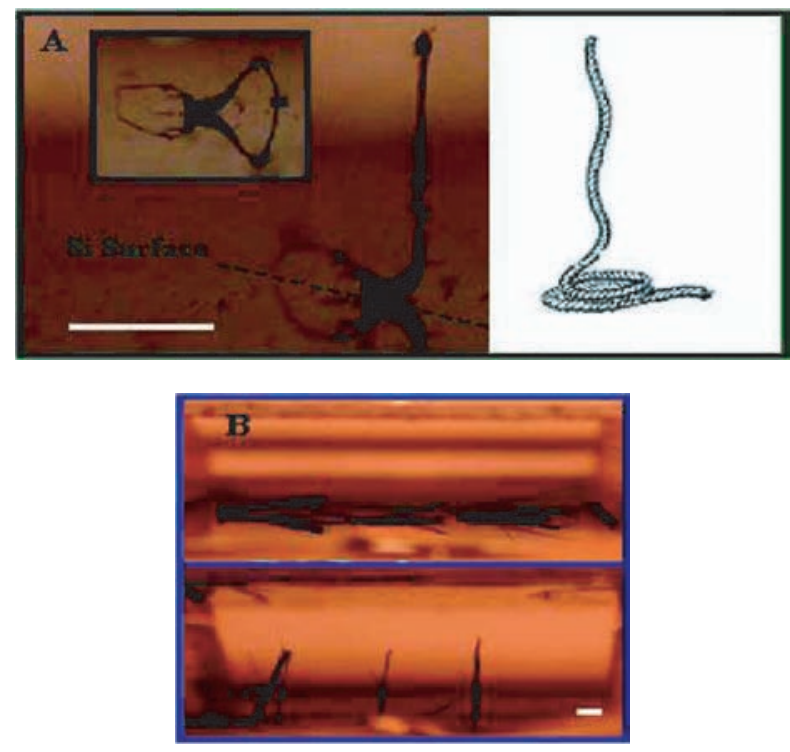

Fig. 3. (a) Response of long SWNT strands to an electric field. (b) Long MWNT ropes under the influence of an electric field. Reprinted with permission from/[85], N. Koratkar et al., J. Nanosci. Nanotechnol. 4, 69 (2004). (c) 2004, American Scientific Publishers.

used by them had some limitations such as: (i) for reliable TEM detection, the thermally excited vibrations must be neither too large nor too small resulting in the restriction of the diameter and length of CNT samples, and (ii) this technique cannot determine the strength (the maximum force per unit area) and the toughness (the elastic energy stored or absorbed by a material) of CNTs. Atomic force microscopy (AFM) was used by Wong et al.$^{87}$ to determine the mechanical properties of MWNTs by pinning them at one end to molybdenum disulfide surfaces. The average value of Young's modulus was found to be $1280 \mathrm{GPa}$. Falvo et al. ${ }^{88}$ observed that MWNTs can be bent repeatedly through large angles without undergoing catastrophic failures by using the tip of an atomic force microscope. All these studies suggest that multilayered CNTs are very strong in nature and are remarkably flexible and resistant to fracture when subjected to large strain. Recently, Gaillard et al. ${ }^{89}$ have shown that the Young's modulus can be measured in individual CVD grown MWNTs by electrostatically driving it into resonance. The bending modulus was found relatively more sensitive to wall defects than the nanotube diameter. However, a comparison of these studies indicates that the values of the mechanical parameters are quite confusing. For instance, a study by Lourie and Wagner ${ }^{90}$ reported the Young's modulus of SWNTs as 2800-3600 GPa and that of MWNTs as 1700-2400 GPa; whereas studies by Yu et al. ${ }^{91,92}$ reported the Young's modulus of SWNTs between 320-1470 GPa and that of MWNTs between 270-950 GPa. The reason behind different numerical values is that some researchers use the total occupied cross sectional area for defining the Young's modulus, while others use the much smaller van der Waals area. ${ }^{65}$ Because of their low density $\left(1.3 \mathrm{~g} / \mathrm{cm}^{3}\right)$, 
materials made of nanotubes are lighter. At the same time, they are more durable. As CNTs have very high aspect ratio, CNT structures are susceptible to structural instability. However, SWNTs have better defined shapes of cylinder than MWNTs, and hence, have less possibilities of structure defects. Therefore, SWNT is preferred over MWNT for carrying out research and for developing applications.

It is extremely challenging to measure the tensile strength of CNTs. Yu et al. ${ }^{91,92}$ found the tensile strength of SWNT bundles in the range of 13 to $52 \mathrm{GPa}$, whereas the value was in the range of 11 to $63 \mathrm{GPa}$ for MWNTs. In case of MWNTs, it was observed that only the outermost layer breaks during the tensile load testing process. Wong et al ${ }^{87}$ measured the bending strength of large-diameter MWNTs. According to them, bending strength is the strain determined at the initial buckling point because the stiffness drops significantly at this point. The average value of bending strength determined by them was $14.2 \pm 8.0 \mathrm{GPa}$, while the maximum value was $28.5 \mathrm{GPa}$. Bending properties of SWNT bundles were studied by Jaroenapibal et al. ${ }^{93}$ by observing the mechanical resonance in a transmission electron microscope. The diameters and lengths of the SWNT bundles ranged from 15 to $70 \mathrm{~nm}$, and from 1 to $10 \mu \mathrm{m}$, respectively. Tunable AC signals were applied to capacitively actuate the bundles. Resonant frequencies ranging from 0.2 to $9 \mathrm{MHz}$ were observed in bundles. They calculated an effective bending modulus of $76 \pm 4 \mathrm{GPa}$ by application of Euler-Bernoulli beam theory to their experimental data. A compressive strength of $100-150 \mathrm{GPa}$ and a compressive strain of $5 \%$ was found by Lourie et al. ${ }^{94}$ as a result of compressive loading of MWNTs. It was also observed that the fracture strength and the elastic limit of nanotubes depend on their chirality. ${ }^{95,96}$

It was found that temperature plays a key role in the strength of CNTs because motion of dislocations is thermally activated. CNTs are brittle at low temperature, irrespective of their diameter and helicity. However, CNTs exhibit flexibility at room temperature due to their high strength and the distortion capability of hexagonal network for relaxing stress. ${ }^{97}$ At high temperature, spontaneous formation of double pentagon-heptagon (or 5/7) pairs were observed in strained CNTs. It was found that such defects depend on the chirality of CNTs and are energetically favored in defect-free armchair nanotubes when the tensile strain is greater than $5 \%$. These defects constitute the onset of the possible plastic deformation of CNTs. ${ }^{98}$ It is important to mention here that the high strength and high stiffness properties of an individual SWNT does not necessarily imply that CNT structures will have the same properties. $^{69}$

CNTs show good load transfer characteristics with metal matrix composites. Efficient load transfer between a matrix and CNTs plays a key role in the mechanical properties of composites and can lead to the development of many superstrong nanocomposites. However, poor load transfer behavior of CNTs in tension compared to compression was observed because only the outermost nanotubes are loaded in tension due to weak interlayer bonding. ${ }^{97}$ In another study, MWNTs were used as reinforcing phase in a polyacrylonitrile (PAN) fiber matrix to produce a PAN-derived carbon/MWNT composite fiber. Significant mechanical property increases were recorded for the composite fibers compared with the samples with no MWNT reinforcement: break strength $+31 \%$, initial modulus $+36 \%$, yield strength $+46 \%$, energy to yield $+80 \%$, and energy to break $+83 \% .{ }^{99}$ Also, the mechanical properties of CNTs and their polymer nanocomposites have been reviewed extensively by Miyagawa et al. ${ }^{100}$ Viscoelasticity in carbon nanotube composites was studied by Suhr et al. ${ }^{101}$ Based on the direct shear testing, they concluded that nanotube fillers offer great improvement in damping without sacrificing mechanical properties and structural integrity.

The specific heat and thermal conductivity of CNTs are dominated by phonons as the electronic contribution is negligible due to low density of free charge carriers. ${ }^{102}$ The experiments by Yi et al. ${ }^{103}$ revealed linear dependence of the specific heat of MWNTs on the temperature over the entire temperature interval (10 to $300 \mathrm{~K})$. MWNTs and bundles of SWNTs with average diameter of $1.3 \mathrm{~nm}$ were used by Mizel et al. ${ }^{104}$ to measure the specific heat in the temperature range $1<T<200 \mathrm{~K}$. While MWNTs exhibited graphite-like behavior, SWNT bundles had steep temperature dependence at low temperatures. The specific heat of SWNT bundles was measured by Lasjaunias et al. ${ }^{105}$ down to a temperature of $0.1 \mathrm{~K}$. The presence of sublinear temperature dependence of specific heat, dominant below $\sim 1 \mathrm{~K}$, was observed. This dependence could not be understood and warrants further investigation into the thermal properties of CNTs. For measuring thermal conductivities of CNTs to isotopic and other atomic defects, the domination of phonons leads to unusual sensitivity of the experiments. ${ }^{106} \mathrm{Kim}$ et al. ${ }^{107}$ determined that at room temperature, the thermal conductivity for an individual MWNT $(>3000 \mathrm{~W} / \mathrm{mK})$ is greater than that of graphite $(2000 \mathrm{~W} / \mathrm{mK})$. It was observed by Zhang et al. ${ }^{108}$ that the value of heat conductivity of zigzag nanotube is maximum, while the chiral nanotube has a minimum value. They also found that the thermal conductivity of SWNTs depends on their length, radius, temperature, and chirality. Therefore, nanoscale devices with different heat conductivities can be made with nanotubes of different chirality.

Properties of CNTs were briefly reviewed in this section. Even though the properties of CNTs have been studied extensively in recent years, only tip of the iceberg has been addressed. A database of properties of CNTs as a function of concentration and type of defects, chemical environment, and temperature should be established to reap maximum benefit. 


\section{CARBON NANOTUBE BASED SENSORS}

As mentioned earlier in this manuscript (Section 1), advantage of CNTs over other materials are due to their small size, high strength, high electrical and thermal conductivity, and high specific area. Therefore, several manuscripts have been published utilizing CNTs as the sensing material in pressure, flow, thermal, gas, optical, mass, position, stress, strain, chemical, and biological sensors. ${ }^{109-177}$ Liu and Dai ${ }^{109}$ demonstrated that piezoresistive pressure sensors can be realized with CNTs. They grew SWNTs on suspended square polysilicon membranes. When uniform air pressure was applied on the membranes, a change in resistance in the SWNTs was observed. Moreover, the membrane was restored to its original condition when the gas was pumped out, indicating that the process is reversible. Dharap et al. ${ }^{110}$ argued that the conventional sensors have disadvantage that they are discrete point, fixed directional, and are not embedded at the material level. To overcome these limitations, they developed a CNT film sensor for strain sensing on macro scale. The sensor was based on the principle that the electronic properties of CNTs change when subjected to strains. As randomly oriented bundles of SWNTs were used by them, the film was isotropic in nature. The isotropic nature of CNT films helps in measuring strains in multiple locations and in different directions. The experimental results revealed nearly linear relationship between the measured change in voltage and the strains in CNT films when they are subjected to tensile and compressive stresses. Wu et al. ${ }^{111}$ demonstrated using first-principle quantum transport calculations, molecular-dynamics simulation and continuum mechanics analysis that hydrostatic pressure can induce radial deformation, and therefore, electrical transition of SWNTs. A pressure-induced metal-to-semiconductor transition in armchair SWNTs was observed, which provides a basis for designing nanoscale tunable pressure sensors. Sotiropoulou and Chaniotakis ${ }^{112}$ developed an amperometric biosensor using CNTs as immobilization matrix. Aligned MWNTs were grown on platinum $(\mathrm{Pt})$ substrate to develop the biosensor. The platinum substrate served as the transduction platform for signal monitoring. The schematic diagram of the CNT array biosensor is shown in Figure 4. The arrays were purified by treatments with acid or air. The acid treatment resulted in the removal of impurities including amorphous carbon that occurred during the production process. The lengths of the nanotubes were also reduced by approximately $50 \%$. Air oxidation resulted in the peeling of the outer graphite layers from the nanotubes. SEM images of the Pt-aligned CNT arrays are shown in Figure 5. After immobilization of the enzyme (glucose oxidase in this case), the response and sensitivity of the acidtreated sensor was found to be very high when compared to the air-treated sensor. In their study, Ghosh et al. ${ }^{113}$ proposed a flow sensor based on SWNTs. The SWNT bundles, having average tube diameter of $1.5 \mathrm{~nm}$, were densely

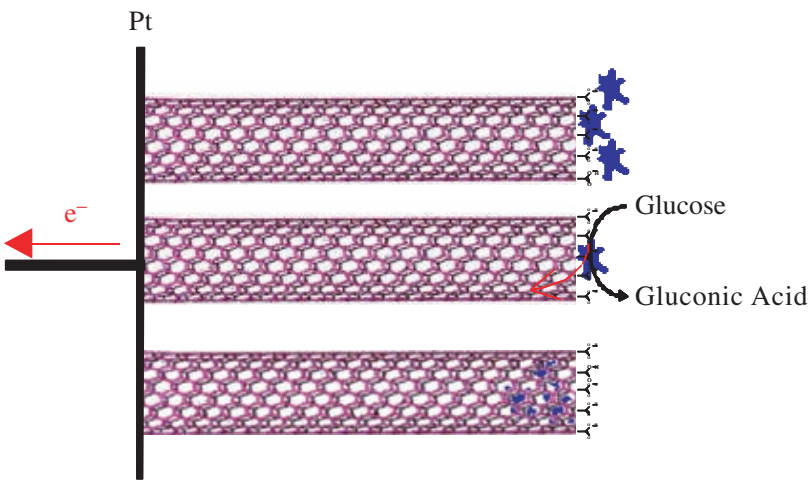

Fig. 4. Schematic diagram of the CNT array biosensor. Reprinted with permission from [112], S. Sotiropoulou and N. A. Chaniotakis, Anal. Bioanal. Chem. 375, 103 (2003). () 2003, Springer Science and Business Media.

packed between two metal electrodes. The sensor used for the experiment was $1 \times 10^{-3} \mathrm{~m}$ long, $2 \times 10^{-4} \mathrm{~m}$ thick, and $2 \times 10^{-3} \mathrm{~m}$ wide. It was observed that SWNTs produce electrical signal in response to fluid flow directly. This is due to the direct scattering of the free carriers from the fluctuating coulombic fields of the ions or polar molecules in the flowing liquid. It was found through experiments that the ionic strength of the flowing liquid significantly affected the induced voltage.

The study by Kong et al. ${ }^{114}$ revealed that the electrical resistance of semiconducting SWNTs dramatically changes when exposed to gaseous molecules such as nitrogen dioxide $\left(\mathrm{NO}_{2}\right)$, ammonia $\left(\mathrm{NH}_{3}\right)$, and oxygen $\left(\mathrm{O}_{2}\right)$. It was found that the response times of nanotube sensors are at least an order of magnitude faster than those based on solidstate sensors. Apart from their small size, semiconducting I SWNTs operate at room temperature with sensitivity as high as $10^{3}$. This forms a basis for building semiconducting
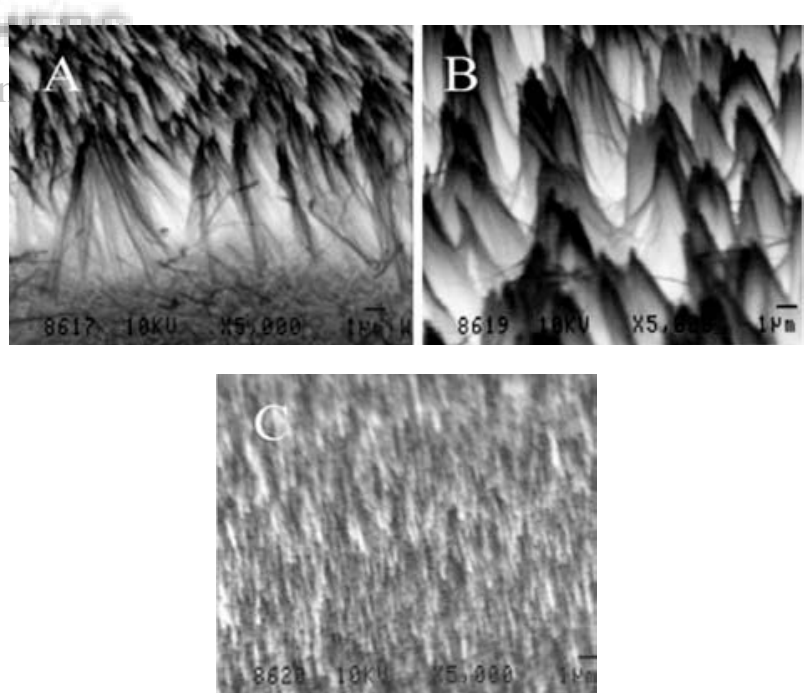

Fig. 5. SEM images of Pt-aligned CNT arrays. (a) In original state, (b) after acid treatment, and (c) after air oxidation. Reprinted with permission from [112], S. Sotiropoulou and N. A. Chaniotakis, Anal. Bioanal. Chem. 375, 103 (2003). (C) 2003, Springer Science and Business Media. 
SWNTs-based chemical sensors. However, Modi et al. ${ }^{115}$ argued that the carbon nanotube gas sensors based on electrical conductance changes have certain limitations, such as poor diffusion kinetics, inability to identify gases with low adsorption energies, and low capability to distinguish between gases or gas mixtures. They also noted that the conductance of CNTs is highly sensitive to changes in moisture, temperature and gas-flow velocity. To overcome these limitations, they proposed gas ionization sensors featuring the electrical breakdown of a range of gases and gas mixtures at the tips of CNTs. The cathode used for the purpose was aluminium and the anode was vertically aligned MWNT film $(\sim 25-30 \mathrm{~nm}$ in diameter, $\sim 30 \mu \mathrm{m}$ in length, and $\sim 50 \mathrm{~nm}$ separation between nanotubes) grown on $\mathrm{SiO}_{2}$ substrate. The electrodes were separated by a glass insulator. The sensors developed by them were found to have good selectivity and sensitivity, and were unaffected by various environmental conditions (moisture, temperature, and gas-flow). Snow et al. ${ }^{116}$ demonstrated that the capacitance of SWNTs is highly sensitive to a wide range of vapors and, therefore, fast, low-power sorption based chemical sensors can be formed using this mechanism. In another study, Jang et al. ${ }^{117}$ proposed a chemical sensor employing laterally grown MWNTs as the active sensing element. The completed MWNT based gas sensor is shown in Figure 6. It was found that the electrical resistance of MWNTs changes upon exposure to air or $\mathrm{NH}_{3}$, as shown in Figure 7. They observed that an increase in measurement temperature and gas concentration resulted in fast response time and higher sensitivity. Surface acoustic waves (SAWs) sensors coated by CNTs were fabricated by Penza et al. ${ }^{118}$ for chemical detection of volatile organic compounds (such as ethanol, ethyl acetate, and toluene in nitrogen). CNT-coated SAW sensors were found to be highly sensitive during experiments. A gas sensor comprising of MWNT-silicon dioxide $\left(\mathrm{SiO}_{2}\right)$ composite was demonstrated by Ong et al. ${ }^{119}$ The sensor was built on the principle that the conductivity and permittivity of the composite changes with the absorption of different gases in the MWNT-SiO ${ }_{2}$ layer. The humidity, temperature and concentrations of carbon dioxide, oxygen, and

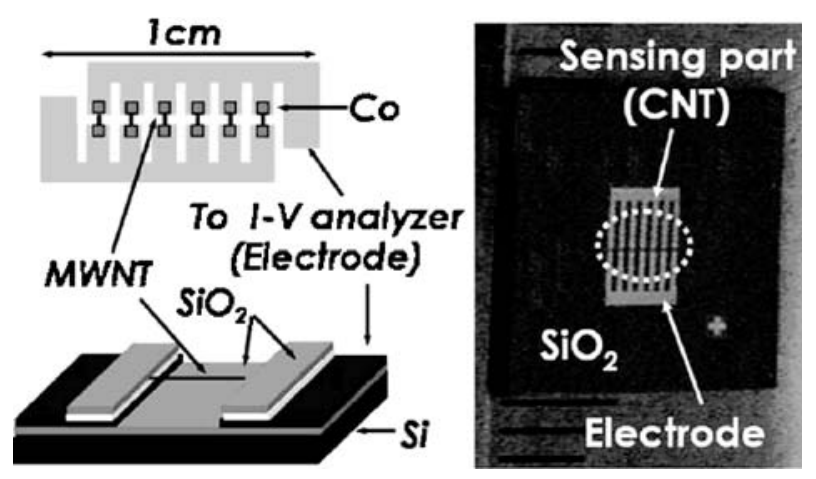

Fig. 6. Photograph of completed MWNT based chemical sensor. Reprinted with permission from [117], Y. T. Jang et al., Sens. Actuators B 99, 118 (2004). (C) 2004, Elsevier.
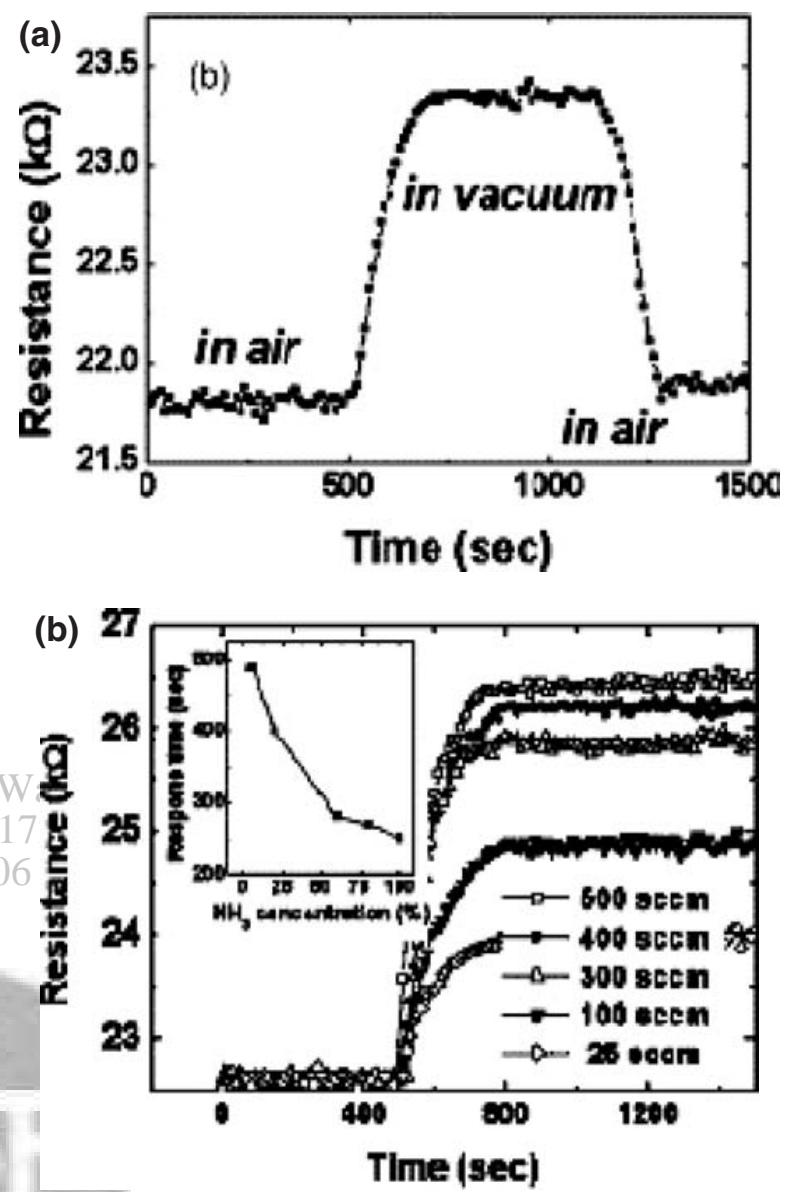

Fig. 7. (a) Electrical resistance of sensor by cycling chamber atmosphere from air to vacuum. (b) Resistance of sensor vs time in a $\mathrm{NH}_{3}$ flows. Reprinted with permission from [117], Y. T. Jang et al., Sens. Actuators B 99, 118 (2004). (C) 2004, Elsevier.

ammonia can be determined by tracking the frequency spectrum of the sensor with a loop antenna. It has the advantage of allowing remote monitoring conditions inside the opaque, sealed containers. Santhanam et al. ${ }^{120}$ developed a chemical sensor using a nanocomposite of MWNTs and poly (3-methylthiophene). Upon exposure to different chloromethanes, the sensor showed a change in electrical resistance. The response time of the sensor was found to be 60 to $120 \mathrm{sec}$.

Wong and $\mathrm{Li}^{121}$ manipulated bulk MWNTs by AC electrophoresis to form resistive elements between Au microelectrodes and demonstrated that MWNTs can potentially serve as temperature sensors. The I-V measurements revealed power consumption in $\mu \mathrm{W}$ range when MWNTs were used in constant current configuration. This indicates that CNTs could be a promising material to fabricate ultra low power consumption thermal sensors. Barone et al. ${ }^{122}$ developed near-infrared optical sensors based on SWNTs making use of the fact that CNTs fluoresce in a region of the near infrared where human tissue and biological fluids are particularly transparent to their emission. $\mathrm{Li}$ and Chou $^{123}$ developed SWNT-based sensors to measure strain 
and pressure at nanoscale on the basis of the shift in resonant frequency of carbon nanotube resonator when subjected to a strain resulting from an external loading. Simulation studies by atomistic modeling revealed that the resonant frequency shifts are linearly dependent on the applied axial strain and the applied pressure. It was also found that the reduction in tube length and diameter enhances the sensitivities of sensors. A room temperature sensor based on carbon nanotubes and nanofibres was developed by Roy et al. ${ }^{124}$ CNTs and nanofibres were grown by them on silicon substrate using acetonitrile and water as electrolyte at an applied DC potential of $20 \mathrm{~V}$. Good sensing properties of films at room temperature were found. Chopra et al. ${ }^{136}$ have reported the development of microwave resonant sensors coated with either SWNTs or MWNTs for detection of ammonia. The experiments revealed that SWNT sensors were more sensitive than the MWNT sensors. The sensor system designed by them is suitable for applications that prohibit the use of physical connections or require non-destructive testing. In their study, Someya et al. ${ }^{141}$ reported alcohol vapor sensors based on SWNT field effect transistors (FETs). The structure of the FET-sensor and the corresponding experimental geometry are schematically shown in Figure 8. The drain current measurements as a function of time are shown in Figure 9. When the saturated ethanol vapor is delivered to the surface, a sharp spike is observed after a few seconds and then the current decreases and reaches a steady value. Recently, new chemical sensors based on single-stranded DNA (ss-DNA) as the chemical recognition site and SWNT field effect transistors as the electronic read-out component have been proposed by Staii et al. ${ }^{144}$ These sensors were able to detect variety of gases with rapid response and fast recovery times. The schematic of the experimental setup and the gases used in the experiment are shown in Figure 10. Figure 11 shows the change in sensor current upon exposure to different gases. These sensors are self-regenerating: samples maintain a constant

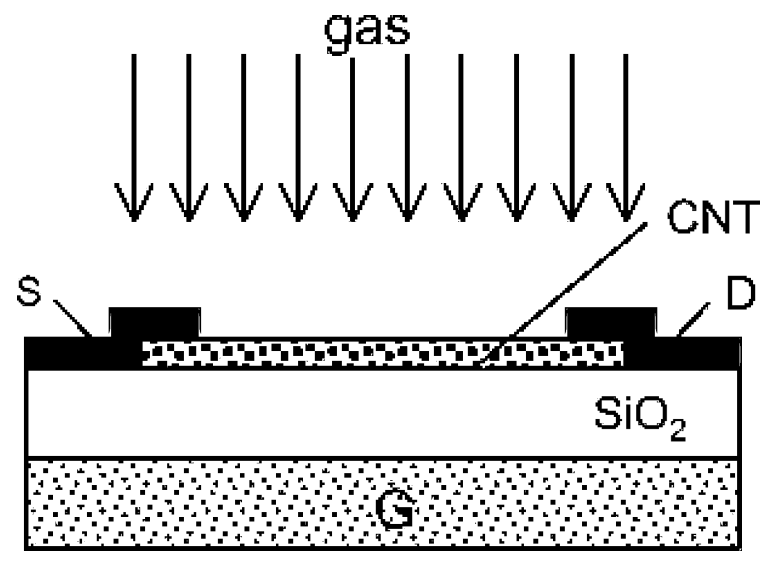

Fig. 8. Cross sectional structure of the FET-based sensor and the experimental geometry. Reprinted with permission from [141], T. Someya et al., Nano Lett. 3, 877 (2003). (C) 2003, American Chemical Society.

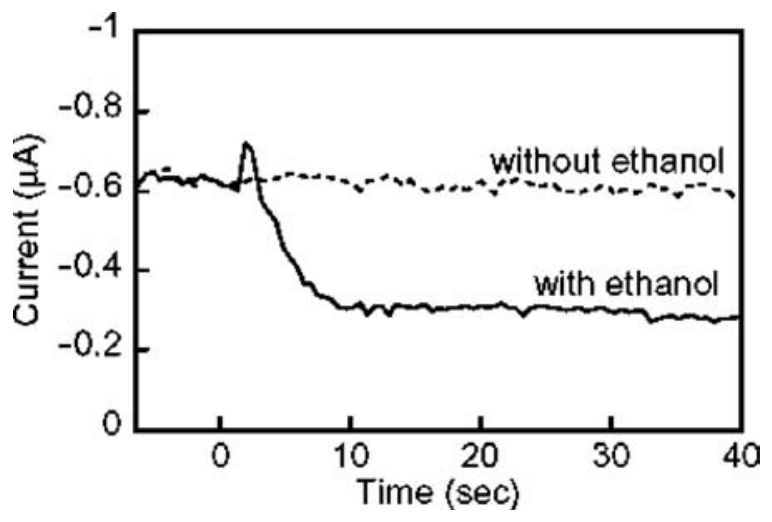

Fig. 9. Drain current measurements as a function of time with a sourcedrain bias of $-100 \mathrm{mV}$ and a gate bias of $-10 \mathrm{~V}$. Reprinted with permission from [141], T. Someya et al., Nano Lett. 3, 877 (2003). (C) 2003, American Chemical Society.

response with no need for sensor refreshing for approximately 50 gas exposure cycles. These features make these sensors suitable for applications ranging from homeland security to disease diagnosis. In another study, an electrochemical sensing platform based on the integration of redox mediators and CNTs in a polymeric matrix has been developed by Zhang and Gorski. ${ }^{151}$ The incorporation of CNTs decreased the overpotential for the mediated

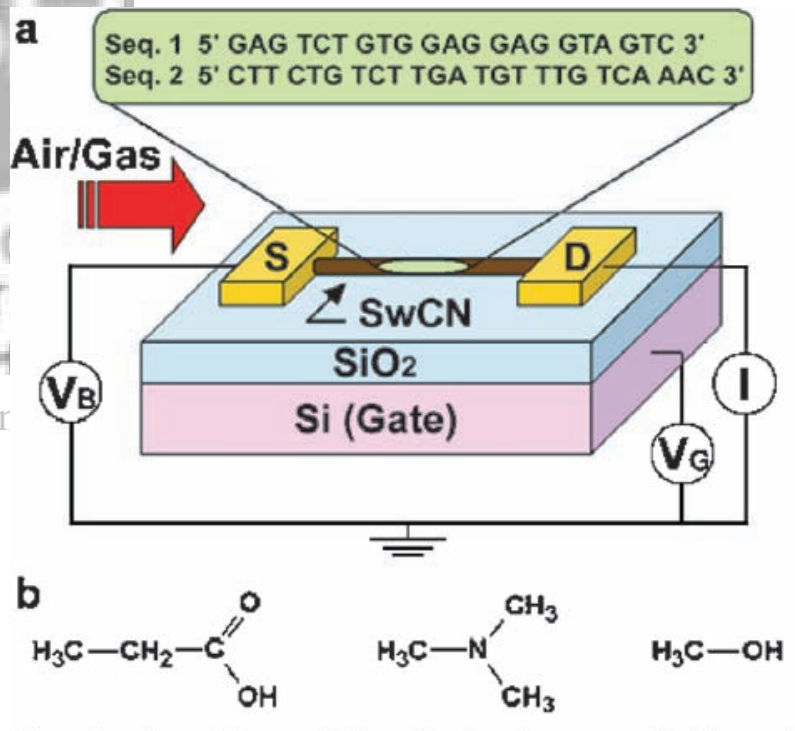

Propionic acid Trimethylamine Methanol<smiles>COP(C)(=O)OC</smiles>

2,6 Dinitrotoluene Dimethyl methylphosphonate

Fig. 10. (a) Schematic of experimental setup. (b) Gases used in the experiment. Reprinted with permission from [144], C. Staii et al., Nano Lett. 5, 1774 (2005). (C) 2005, American Chemical Society. 

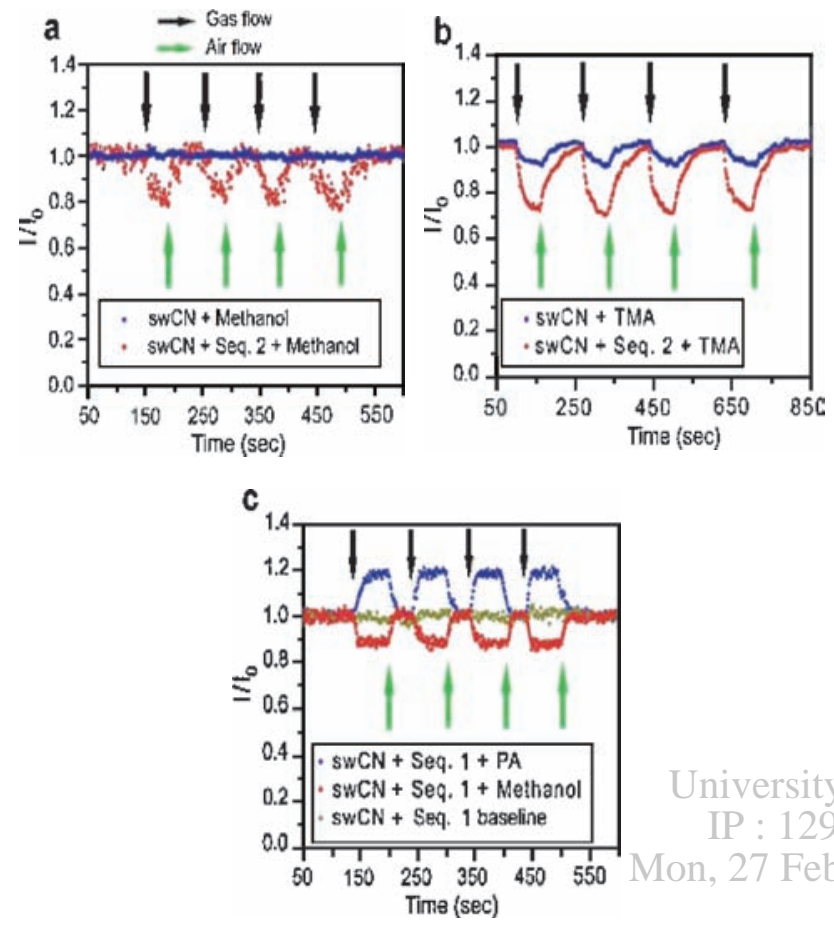

Fig. 11. Change in sensor current upon exposure to different gases. Reprinted with permission from [144], C. Staii et al., Nano Lett. 5, 1774 (2005). (C) 2005, American Chemical Society.

process by an extra $0.30 \mathrm{~V}$ and reduced the response time from 70 seconds to approximately 5 seconds. The concept of CNT-facilitated redox mediation in polymeric matrixes can find useful applications in electrochemical devices

Table I. Summary of CNT sensing ability to different gases/agents.

\begin{tabular}{|c|c|c|c|}
\hline Gas/agent & Ref. & Gas/agent & A Ref. E \\
\hline $\mathrm{NH}_{3}$ & $\begin{array}{c}{[114],[115],[117],} \\
{[119],[136],[137],} \\
{[143],[152],[153],} \\
{[161]}\end{array}$ & $\mathrm{CO}$ & $\begin{array}{l}{[137],[147],} \\
{[174],[175]} \\
\text { PLEL, }\end{array}$ \\
\hline $\mathrm{CO}_{2}$ & {$[119]$} & $\mathrm{NO}$ & Deli[165] d \\
\hline $\mathrm{O}_{2}$ & [115], [119], [137] & $\mathrm{He}$ & [115], [137] \\
\hline $\mathrm{NO}_{2}$ & $\begin{array}{c}{[114],[139],[150],} \\
{[152],[163],[165],} \\
{[176]}\end{array}$ & Glucose & $\begin{array}{l}\text { [112], [135], } \\
{[140],[142],} \\
{[146],[149],} \\
{[168],[169]}\end{array}$ \\
\hline $\mathrm{CH}_{4}$ & [124] & $\mathrm{H}_{2} \mathrm{O}_{2}$ & [158], [169] \\
\hline $\mathrm{H}_{2}$ & [132], [177] & $\mathrm{SF}_{6}$ & [159] \\
\hline $\mathrm{N}_{2}$ & [115], [137] & Air & [115], [117] \\
\hline $\mathrm{Ar}$ & [115], [137] & DNA & {$[171],[172]$} \\
\hline Ethanol & $\begin{array}{c}{[116],[118],[141],} \\
{[146],[165]}\end{array}$ & Methanol & [116], [144] \\
\hline Choline & {$[158]$} & Nitrotoluene & {$[150]$} \\
\hline Chloromethane & [115], [120] & Acetylene & {$[165]$} \\
\hline Propionic Acid & [144] & Trimethylamine & [144] \\
\hline Dinitrotoluene & [116], [144] & $\begin{array}{c}\text { Dimethyl } \\
\text { phosphonate }\end{array}$ & [116], [144] \\
\hline $\begin{array}{l}\text { Organophosphorus } \\
\text { pesticides }\end{array}$ & [160] & $\begin{array}{l}\text { Other chemical } \\
\text { vapors }\end{array}$ & $\begin{array}{c}\text { [116], [118], } \\
{[129],[130],} \\
{[131],[137],} \\
{[155],[157],} \\
{[173]}\end{array}$ \\
\hline
\end{tabular}

such as sensors, biosensors, and biological fuel cells and reactors.

Several types of carbon nanotube sensors were reviewed in this section. A summary of sensing ability of different gases/agents is given in Table I. The next section will outline the present and future applications of CNT-based sensors.

\section{APPLICATIONS OF CARBON NANOTUBE BASED SENSORS}

In past, several studies have been reported indicating potential applications of CNTs. ${ }^{2,43,65,66,178-181}$ However, this manuscript attempts to report, exclusively, the existing and future applications of CNT-based sensors. The following sections detail the areas where CNT-based sensors can be potentially applied.

\subsection{Biomedical Industry}

It is believed that CNTs incorporated sensors can bring dramatic changes to the biomedical industry. There are certain cases such as diabetes, where regular tests by patients themselves are required to measure and control the sugar level in the body. Children and elderly patients may not be able to perform this test properly. Another similar example is regular tests of persons exposed to hazardous radiations or chemicals. The objective in these cases is to detect the disease in its early stage so that appropriate clinical action can be taken. According to Bhargava, ${ }^{182}$ implantable sensors can be useful in health assessment. CNT-based nanosensors have the advantages that they are thousands of times smaller than even MEMS sensors and consume less power. Also, they are less sensitive to variations in temperature (compared to silicon piezoresistors). ${ }^{183}$ This enables them to perform better in many of the biomedical sensing applications. Therefore, CNT-based nanosensors are highly suitable as implantable sensors. Implanted sensors can be used for monitoring pulse, temperature, blood glucose, and diagnosing diseases. ${ }^{184-186}$ Besides, CNTs can be used for repairing damaged cells or killing them by targeting tumors by chemical reactions. Implantable nanosensors can also monitor heart's activity level and regulate heartbeats by working with an implantable defribulator. ${ }^{187} \mathrm{CNT}$ based nanobiosensors may also be used to detect DNA sequences in the body. ${ }^{171}$ These instruments detect a very specific piece of DNA that may be related to a particular disease. ${ }^{172}$ Therefore, these sensors can possibly diagnose patients as having specific sequences related to a cancer gene. The use of CNT-based sensors will avoid problems associated with the current much-larger implantable sensors, which can cause inflammation, and eliminate the need to draw and test blood samples. The devices can be administered transdermally, or through the skin, avoiding the need for injections during space missions. ${ }^{188}$ Biosensors can also be used for monitoring total cholesterol in 
blood. ${ }^{164} \mathrm{CNT}$ chemical sensors for liquids can be used for blood analysis (for example, detecting sodium or finding $\mathrm{pH}$ value). ${ }^{189}$

As pressure sensors incorporating CNTs are fabricated, they can find application in many diagnostic and therapeutic devices. Pressure sensors can be used in eye surgery, hospital beds, respiratory devices, patient monitors, inhalers, and kidney dialysis machines. ${ }^{190,191}$ During eye surgery, fluid is removed from the eye and, if required, cleaned and replaced. Pressure sensors measure and control the vacuum that is used to remove the fluid, and provide input to the pump's electronics by measuring barometric pressure. Hospital bed mattresses for burn victims consist of pressure sensors that regulate a series of inflatable chambers. To reduce pain and promote healing, sections can be deflated under burn areas. Pressure sensors can also be used for sleep apnea (a cessation of breathing during sleep) detection. The pressure sensor monitors the changes in pressure in inflated mattresses. If no movement is found for a certain period of time, the sleeper is awakened by an alarm. ${ }^{191}$ Pressure sensing technology is used in both invasive and noninvasive blood pressure monitors. Many patients who use inhalers activate their inhalers at inappropriate time resulting in insufficient dose of medication. Pressure sensors in the inhalers identify the breathing cycle and release the medication accordingly. ${ }^{190}$ During kidney dialysis, blood flows from the artery to the dialysis machine and after cleaning flows back into the vein. Waste products are removed from the blood through osmosis and move across a thin membrane into a solution that has blood's mineral makeup. ${ }^{192}$ Using pressure sensors, the operation of the dialysis system can be regulated by measuring the inlet and outlet pressures of both the blood and the solution. Intelligent pressure sensing systems play an important role in portable respiratory devices that consist of both diagnostic (spirometers, ergometers, and plethysmographs) and therapeutic (ventilators, humidifiers, nebulizers, and oxygen therapy equipment) equipments. They serve patients with disorders of asthma, sleep apnea, and chronic obstructive pulmonary disease. These equipments measure pressure by known fluid dynamic principles. ${ }^{190}$

CNT-based flow sensors can be used in micromachines that work in a fluidic environment such as heart pacemakers that need neither heavy battery packs nor recharging. ${ }^{113}$ Flow sensors can also be used for precise measurements of gases utilized by respiratory apparatuses during surgery and automatic calculation of medical treatment fees based on the output data leading to reduced hospital costs and more accurate calculation.

\subsection{Automotive Industry}

Because of the quest to improve performance, reduce cost, and enhance the reliability, sensors have a substantial utility in the automotive industry and their influence is expected to increase while designing the vehicles of the future. ${ }^{193}$ They are used to acquire information about vehicle parameters such as pressure, vehicle altitudes, flow, temperature, heat, humidity, speed and acceleration, exhaust gas, and engine knock and torque. Apart from enabling new desirable features, CNT-based sensors are simply replacing old technologies with cheaper and more reliable devices.

It has been mentioned earlier in this manuscript (Section 4) that many sensors such as pressure, flow, thermal, gas, and chemical sensors can be realized using CNTs. A pressure sensor can be used to determine when an air filter is dirty. This can be done by measuring the pressure difference at the filter's air intake and on the other side of the diaphragm. They can also be used to calculate mass airflow rate, engine speed and air temperature by measuring the pressure from intake fold. Pressure measurements are often used for altitude compensation. In vehicles fitted with active-suspension systems, a pressure sensor may be required to control variable-stiffness air springs or possibly adjustable dampers. ${ }^{194}$

Crash sensing is very important from sensing point of view. Sensors with fast response features are required in this case as the decision to fire air bags should be made in fractions of seconds. ${ }^{195}$ CNT-based sensors can be very useful in this case. Vehicle dynamic control (VDC), rollover detection, and antitheft systems are other important areas where CNT-based sensors can be potentially applied. VDC systems assist the driver when the automobile starts skidding. CNT-based sensors can be employed to detect the lateral sliding of the vehicle. If lateral sliding is detected, single-wheel braking or torque reduction can be used to get the vehicle back in line. Rollover detection is rapidly being adopted by vans, trucks, and sports utility vehicles manufacturers because of their higher centre of gravity. ${ }^{195}$ CNT-based sensors can be used to find the roll angle and roll rate to determine if the vehicle is tipping over.

To prevent stealing of cars, antitheft systems are provided by the automakers. Conventional antitheft systems incorporate tilt detection systems. The drawback with this system is that its not possible to park the car at higher inclinations. Also, conventional sensors don't perform well in the widely varying automotive temperature environment. ${ }^{195}$ CNT-based sensors can find promising applications in this case. Other areas, where CNT-based sensors can find application are ignition control, headway control, transmission control, vehicle navigation, tyre condition, and cabin air quality monitoring.

\subsection{Food Industry}

Sensors and biosensors have been widely used in food industry to provide safety and quality control of food products as the contamination of foods caused by bacterial pathogens may result in numerous diseases. ${ }^{196}$ Efficient quality assurance is becoming increasingly important in 
the food industry. On one hand, consumers expect adequate quality at a given price, good shelf-life, and high safety; on the other hand, food producers are increasingly asking for efficient control methods, in particular through on-line and at-line quality sensors to satisfy consumers and regulatory requirements, and to improve production feasibility, quality sorting, automation, reduction of production time and production cost. These factors are acting as a driving force for the development of new sensors and sensing systems. By taking advantages of nanotechnology and unique properties of carbon nanotubes, and by avoiding the main disadvantages of conventional methods (such as multistep assay and time consuming processing), CNT-based sensors and biosensors show great potential for applications in the food industry.

CNT-based biosensors can be used in meat freshness evaluation. Luong et al. ${ }^{197}$ reported a MWNT-based biosensor for non-mediator detection of putrescine. 3-Aminopropyltriethoxysilane (APTES) solubilized MWNTs were coated on glassy carbon electrodes to impose the interaction and electron exchange between redox-enzymes and electrode interface. The APTES modified CNTs served as an immobilization matrix for putrescine oxidase (POx).

Apart from CNT-based biosensors, CNT-based gas sensors can also be used for meat freshness monitoring during shipment, storage, and processing. After constant storage, certain volatile components (such as ethyl acetate) are released due to the initial bacterial putrefaction of meat. ${ }^{198}$ By detecting the concentration of these chemicals, the quality of meat can be controlled. Philip et al. ${ }^{173}$ reported a CNT/Polymer gas sensor that can detect different organic vapors including ethyl acetate. The sensing material in this gas sensor is CNT/polymethylmethacrylate (PMMA) composite thin film. Experimental results show that the resistance changes of surface-modified MWNT/PMMA response to ethyl acetate is in the order of 30. The use of a CNT-based gas sensor provides a non-destructive, noncontact method of food analysis, which is highly desirable for quality control in food industry.

CNT-based chemical sensor can be used to detect undesired chemical residues resulting from animal drugs, food additives, herbicides, pesticides, and other environmental contaminants in raw and processed foods. Promising research areas for CNT-based sensors include evaluation of the quality of fruits and vegetables by detecting their damage.

\subsection{Environmental Monitoring}

CNT-based gas sensors can offer improved performance in real-time monitoring of combustible gas alarms, gas leak detection/alarms, biowarfare (e.g., monitoring explosives such as TNT or RDX and nerve agents such as GB or VX), environmental pollution monitoring, and cooking controls, etc. Unlike conventional solid-state gas sensors, which require relatively high temperatures to achieve significant sensitivity for gas molecules, CNT-based miniaturized gas sensors can work at room temperature. ${ }^{114}$ Moreover, not limited by the microfabrication techniques, gas sensors based on CNTs can be built in different geometry and offer reliable response. ${ }^{174}$

CNT-based carbon monoxide (CO) sensor ${ }^{147,174,175}$ can be used to control ventilation system in car parks. In car parks, mechanical ventilation systems with exhaust fans are installed to ensure that the level of $\mathrm{CO}$ does not exceed safe limits. According to the different level of $\mathrm{CO}$ concentration detected by $\mathrm{CO}$ sensor, the fans in ventilation system can be triggered either starting or stopping or operating with variable speed drives. The circumstances where significant diesel traffics are expected, CNT-based $\mathrm{NO}_{2}$ sensor can be applied. ${ }^{176}$

CNT-based optical sensors can provide useful tools for remote in-situ monitoring. Their small size would make them suitable for sensing intracellular/intercellular physiological and biological parameters in microenvironments. ${ }^{199}$ CNT-based electrochemical biosensor can be used for wastewater monitoring. ${ }^{200}$ The results of wastewater real samples tests were found to be in good agreement with the results of other genotoxicity tests, which confirmed the applicability of the CNT biosensor for real samples.

\subsection{Agriculture and Fishing Industry}

Besides medical and domestic applications for human comfort, another significant application of CNT-based humidity sensors is to monitor humidity in green house agriculture. Humidity and temperature conditions impact the quantity and quality of the product directly. Experimental results have shown that MWNT-coated quartz crystal microbalance humidity sensor can monitor relative humidity over the range of 5-97\% RH with a response and recovery time of about 60 and 70 seconds respectively. ${ }^{157}$ In addition, in green house and controlled environment garden (CEG) atmospheres, carbon dioxide $\left(\mathrm{CO}_{2}\right)$ is utilized by plant for photosynthesis in which $\mathrm{CO}_{2}$ and water combine with the aid of light energy to form sugar. Some of these sugars are converted into complex compounds that increase dry solid plant substances for continued growth to final maturity. However, plants may not grow properly if the concentration of $\mathrm{CO}_{2}$ is too high because the $\mathrm{CO}_{2}$ would dissolve in water making carbonic acid, which further makes the soil and air too acidic. CNT-based $\mathrm{CO}_{2}$ sensors can be used to monitor the concentration of $\mathrm{CO}_{2}$ within the green house or CEG to achieve an optimal environment for plants' growth. ${ }^{119}$

CNT-based pressure sensors can be used for uniform spraying of liquid fertilizer, insecticides, and herbicides. A spraying system, usually pulled by a tractor, consists of a tank, pump, associated valves, and a series of nozzles spaced at equal intervals. Pressure sensor is used to sense nozzle pressure. According to the variation of the tractor speed, a microprocessor controls liquid pressure in order to 
achieve uniform spraying of chemicals. Farmers will benefit from uniform spraying by avoiding additional expense of fertilizers and pesticides, and resultant high crop yields.

In fishing industry, good $\mathrm{pH}$ balance of water quality ensures survival and growth of cultured fishes and shrimps. CNT-based $\mathrm{pH}$ sensors can be used to determine $\mathrm{pH}$ value when selecting location for farming so as to avoid abnormality in fishing grounds and hatcheries. ${ }^{201}$

\subsection{Manufacturing Industry}

CNT based hydrogen gas sensor can be used in hydrogen monitoring and control for petroleum transformation, welding, rocket engines, and fuel cells. Recent research shows that raw SWNTs and palladium modified SWNT thin films are good sensing materials for hydrogen sensing. ${ }^{132}$ The sensor has high sensitivity to hydrogen over a wide temperature range (from room temperature to $170{ }^{\circ} \mathrm{C}$ ). ${ }^{177}$

CNT based strain and pressure sensors can be used for strain and pressure measurements in manufacturing industry. For example, in aircraft manufacturing, strain measurement of the skin of aircraft is critical. Strain and pressure sensors play an important role in this area. Dharap et al. reported a SWNT film sensor for macro scale strain sensing. ${ }^{110}$ In their experiments, a SWNT film was embedded into brass specimen and external probes were used to sense multidirectional and multiple location strains. A nearly linear response of voltage change was achieved to the change of strains in the SWNT film.

CNT-based sensors can also be used in the integrated circuits (IC) industry for IC performance evaluation. Wright et al. ${ }^{202}$ have proposed CNT-based sensors for carrying out IC performance monitoring functions in the substrate level as well as on the problem of interfacing the molecular devices with the existing metallic circuitry of the ICs. This approach of identification of failed ICs on electronic circuit boards would drastically reduce the cost of the test equipment development and maintenance.

\subsection{Security and Others}

High sensitivity and low power consumption make CNTbased sensors suitable, especially, for high accuracy and battery-powered applications, e.g., military. Since purified CNTs have very large surface area $\left(1587 \mathrm{~m}^{2} / \mathrm{g}\right)^{203}$ and extremely high conductivity, CNT composite show low threshold and sharp slope of percolation conductivity around the threshold. Thus, the sensors using CNT composite as sensing materials have higher sensitivity. ${ }^{204}$

CNT-based sensors can be potentially applied in defense and homeland security. ${ }^{144}$ They can be deployed in unmanned defense systems such as unmanned aerial vehicles. The meaning of security here is twofold: (i) security from infectious diseases and (ii) security from bombs and weapons at the ports of entry. Infectious diseases are becoming a matter of national security for many countries. ${ }^{199}$ In the past, movement of infectious diseases such as SARS, TB, and malaria across borders have adversely affected the industrial production, agricultural output, and social and economic stability. CNT-based biosensors can be used to detect these diseases at the ports of entry. CNT-based chemical sensors can be used as electronic noses to detect hidden bombs, chemical weapons in luggage, vehicles, and aircraft. ${ }^{116,144}$ These electronic noses can sense the vapors emitted by explosives and chemical weapons. They are smaller and less expensive than training bomb-sniffing dogs, which are presently used in airport, maritime ports and border. The advantages of the electronic noses allow them to be widely deployed in potential terrorist targets in larger numbers.

A MWNT infrared detector has been fabricated and tested by Liu et al. ${ }^{205}$ The response time of the detector is about $400 \mathrm{~ms}$ to a $250 \mathrm{~W}$ infrared lamp source placing $50 \mathrm{~cm}$ away. Theoretical analysis implies that CNTs can be used to fabricate high-density focal plane array for infrared detection and those infrared sensors have a broad wavelength response range, low-noise level, and good compatibility with semiconductor fabrication process. Besides the above mentioned applications, CNT-based acoustic and optical sensors can be used for breath alcohol detection at room temperature. ${ }^{206}$

\section{CHALLENGES}

Within fifteen years of the discovery of CNTs, the merits of CNT-based sensors have shown strong potential to make huge impact in future sensor industry. However, the realworld opportunities of these sensors will not emerge and unfold overnight. There remain challenges to be addressed before the full potential of CNTs for sensor applications can be realized. For example, the production of pure and uncontaminated nanotubes is very costly. There are only Ifew companies that produce CNTs for commercial applications. In addition to it, there is a lack of detailed understanding of growth mechanism of CNTs. ${ }^{207}$ As a result, an efficient growth approach to structurally perfect nanotubes at large scales is currently not available. Secondly, it is difficult to grow defect-free nanotubes continuously to macroscopic lengths. ${ }^{40}$ Thirdly, control over nanotubes growth on surfaces is required in order to obtain largescale ordered nanowire structures. Currently, dispersion of CNTs onto a polymer matrix is very difficult. CNTs agglomerate because of intrinsic van der Waals attraction among the tubes, coupled with their high aspect ratio and surface area. ${ }^{44}$ Finally, controlling the chirality of SWNTs by any existing growth method is very difficult. ${ }^{40}$ Recently, Wang et al. ${ }^{208}$ have demonstrated the continued growth of SWNTs from ordered arrays of open-ended SWNTs in a way analogous to epitaxy. Although a pathway for control over both the diameter and chiral angle during synthesis has been demonstrated, the process has been found 
sensitive to SWNT surface conditions and extraneous environmental species. Therefore, in short, the optimization of production parameters and the control on the growth of nanotubes is to be mastered.

In addition to the challenges at the fabrication level, the low dimensional geometry results in structural instability, which is an important issue because at larger strains, CNTs are prone to buckling, kink forming, and collapse. ${ }^{69}$ Another issue concerning the use of CNTs is their toxicity. ${ }^{209,210} \mathrm{On}$ the basis of their experiments, researchers have suggested that CNTs possess health risks. They reasoned that humans can potentially be exposed to CNTs by inhalation because unprocessed CNTs are lightweight and, therefore, can become airborne. If CNTs reach the lung, they can agglomerate and fill the air passages that may lead to suffocation. It was shown by Larn et al. ${ }^{211}$ that exposure to SWNTs leads to the development of granulomas in rodents. Another study has revealed that the exposure of cultured human skin cells to SWNTs results in oxidative stress and loss of cell viability. ${ }^{212}$. This is not unexpected since graphite and carbon materials have been associated with increased dermatitis and keratosis. These reports warrant an in-depth study about the toxicology of CNTs to come up with a final conclusion with respect to their acceptance by the human immune system. Lastly, the time from proof of concept in the laboratory of the CNT-based devices to the commercial market place should be reduced as the competition from other novel materials and technologies continue to emerge.

\section{CONCLUSIONS}

Research activity in the areas related to CNTs has seen phenomenal growth in the last one and half decade. In this paper, an attempt has been made to provide the most contemporary overview possible of CNT-based sensors and their potential applications. The exceptional properties, which allow CNTs to be used in sensors and other devices, have also been reviewed. The use of CNT will increase the sensitivity and dynamic range of sensors. The developments of integrated circuits, which can detect, convert, process, and amplify minute signals, is required from the microelectronic community. We need an effective interface to the nano-material in order to extract the embedded signals. It is expected that many applications of CNT-based sensors will be explored in future as the interest of the nanotechnology research community in this field increases. However, CNTs have yet to cross many technological hurdles in order to fulfill their potential as the preferred material for sensor applications.

Acknowledgments: The first author would like to thank Dr. D. Das, University of Ottawa, for critical review of the manuscript. The authors would also like to thank Prof. N. Koratkar and Prof. M. Misra for their help in the form of sending reprints of their articles.

\section{References and Notes}

1. S. Ijima, Nature 354, 56 (1991).

2. M. S. Dresselhaus, Nature 358, 195 (1992).

3. M. S. Dresselhaus, G. Dresselhaus, and P. C. Eklund, Science of Fullerenes and Carbon Nanotubes, Academic Press, New York (1996).

4. http://www.lbl.gov.

5. S. Ijima, P. M. Ajayan, and T. Ichihashi, Phys. Rev. Lett. 69, 3100 (1992).

6. T. W. Ebbesen and P. M. Ajayan, Nature 358, 220 (1992).

7. S. Ijima and T. Ichihashi, Nature 363, 603 (1993).

8. D. S. Bethune, C. H. Kiang, M. S. de Vries, G. Gorman, R. Savoy, J. Vazquez, and R. Beyers, Nature 363, 305 (1993).

9. C. Liu, H. T. Cong, F. Li, P. H. Tan, H. M. Cheng, K. Lu, and B. L. Zhou, Carbon 37, 1865 (1999).

10. M. V. Antisari, R. Marazzi, and R. Krsmanovic, Carbon 41, 2393 (2003).

11. H. Zhu, B. Jiang, C. Xu, and D. Wu, J. Phys. Chem. B 107, 6514 (2003).

12. C. Journet, W. K. Maser, P. Bernier, A. Loiseau, M. L. de la Chapelle, S. Lefrant, P. Deniard, R. Lee, and J. E. Fischer, Nature 388, 756 (1997).

13. H. Li, L. Guan, Z. Shi, and Z. Gu, J. Phys. Chem. B 108, 4573 (2004).

14. M. C. Paladugu, K. Maneesh, P. K. Nair, and P. Haridoss, J. Nanosci. Nanotechnol. 5, 747 (2005).

15. A. Thess, R. Lee, P. Nikolaev, H. J. Dai, P. Petit, J. Robert, C. H. Xu, Y. H. Lee, S. G. Kim, A. G. Rinzler, D. T. Colbert, G. E. Scuseria, D. Tomanek, J. E. Fischer, and R. E. Smalley, Science 273, 483 (1996).

16. S. Arepalli, P. Nikolaev, W. Holmes, and B. S. Files, Appl. Phys. Lett. 78, 1610 (2001).

17. C. D. Scott, S. Arepalli, P. Nikolaev, and R. E. Smalley, Appl. Phys. A 72, 573 (2001).

18. N. Braidy, M. A. El Khakani, and G. A. Botton, J. Mater. Res. 17, 2189 (2002).

19. S. Takahashi, T. Ikuno, T. Oyama, S. I. Honda, M. Katayama, T. Hirao, and K. Oura, J. Vac. Soc. Jpn. 45, 609 (2002).

20. S. Arepalli, J. Nanosci. Nanotechnol. 4, 317 (2004).

21. P. C. Eklund, B. K. Pradhan, U. J. Kim, Q. Xiong, J. E. Fisher, A. D. Friedman, B. C. Holloway, K. Jordan, and M. W. Smith, Nano Lett. 2, 561 (2002).

22. R. L. Vanderwal, G. M. Berger, and T. M. Ticich, J. Nanosci. Nanotechnol. 3, 241 (2003).

23. M. J. Yacaman, M. M. Yoshida, L. Rendon, and J. G. Santiesteban, Appl. Phys. Lett. 62, 202 (1993).

24. W. Z. Li, S. S. Xie, L. X. Qian, B. H. Chang, B. S. Zou, W. Y. Zhou, R. A. Zhao, and G. Wang, Science 274, 1701 (1996).

25. L. C. Qin, J. Mater. Sci. Lett. 16, 457 (1997).

26. Y. C. Choi, D. J. Bae, Y. H. Lee, B. S. Lee, G. S. Park, W. B. Choi, N. S. Lee, and J. M. Kim, J. Vac. Sci. Technol. A 18, 1864 (2000).

27. V. K. Varadan and J. Xie, Smart Mater. Struc. 11, 610 (2002).

28. D. Park, Y. H. Kim, and J. K. Lee, Carbon 41, 1025 (2003).

29. J. B. Nagy, G. Bister, A. Fonseca, D. Mehn, Z. Konya, I. Kiricsi, Z. E. Horvath, and L. P. Biro, J. Nanosci. Nanotechnol. 4, 326 (2004).

30. K. Mukhopadhyay and G. N. Mathur, J. Nanosci. Nanotechnol. 2, 197 (2002)

31. L. Dong, J. Jiao, S. Foxley, D. W. Tuggle, C. L. Mosher, and G. H. Grathoff, J. Nanosci. Nanotechnol. 2, 155 (2002).

32. R. Seidel, G. S. Duesberg, E. Unger, A. P. Graham, M. Liebau, and F. Kreupl, J. Phys. Chem. B 108, 1888 (2004).

33. S. Delpeux, K. Szostak, E. Frackowiak, S. Bonnamy, and F. Beguin, J. Nanosci. Nanotechnol. 2, 481 (2002).

34. J. K. Vohs, J. J. Brege, J. E. Raymond, A. E. Brown, G. L. Williams, and B. D. Fahlman, J. Am. Chem. Soc. 126, 9936 (2004). 
35. B. Q. Wei, R. Vajtai, Y. Jung, J. Ward, R. Zhang, G. Ramanath, and P. M. Ajayan, Nature 416, 495 (2002).

36. A. R. Harutyunyan, B. K. Pradhan, U. J. Kim, G. G. Chen, and P. C. Eklund, Nano Lett. 2, 525 (2002).

37. S. Chaisitsak, A. Yamada, and M. Konagai, Diam. Rel. Mater. 13, 438 (2004).

38. T. W. Ebbesen (ed.), in Carbon Nanotubes: Preparation and Properties, CRC Press, Boca Raton (1997), p. 139.

39. S. Farhat, I. Hinkov, and C. D. Scott, J. Nanosci. Nanotechnol. 4, 377 (2004).

40. H. Dai, in Topics in Applied Physics, edited by M. S. Dresselhaus, G. Dresselhaus, and P. Avouris, Springer, New York (2001), Vol. 80, p. 29.

41. S. Arepalli, W. A. Holmes, P. Nikolaev, V. G. Hadjiev, and C. D. Scott, J. Nanosci. Nanotechnol. 4, 762 (2004).

42. S. Maheshwar, P. R. Apte, S. C. Purandare, and R. Zacharia, J. Nanosci. Nanotechnol. 5, 288 (2005).

43. V. N. Popov, Mater. Sci. Eng. $R$ 43, 61 (2004).

44. H. Dai, Surf. Sci. 500, 218 (2002).

45. K. Awasthi, A. Srivastava, and O. N. Srivastava, J. Nanosci. Nanotechnol. 5, 1616 (2005).

46. L. Thien-Nga, J. M. Bonard, R. Gaal, and L. Forro, Appl. Phys. Lett. 80, 850 (2002).

47. A. C. Dillon, M. Yudasaka, and M. S. Dresselhaus, J.PNanosci. Nanotechnol. 4, 691 (2004).

48. B. Zhao, M. E. Itkis, S. Niyogi, H. Hu, D. E. Perea, and R. C. Haddon, J. Nanosci. Nanotechnol. 4, 995 (2004).

49. T. W. Ebbesen, P. M. Ajayan, H. Hiura, and K. Tanigaki, Nature 367, 519 (1994).

50. S. Gajewski, H. E. Maneck, U. Knoll, D. Neubert, I. Dorfel, R. Mach, B. Strauss, and J. F. Friedrich, Diam. Rel. Mater. 12, 816 (2003).

51. H. Hiura, T. W. Ebbesen, and K. Tanigaki, Adv. Mater. 7,275 (1995).

52. L. Vaccarini, C. Goze, R. Aznar, V. Micholet, C. Journet, and P. Bernier, Synth. Met. 103, 2492 (1999).

53. H. Y. Kim, W. B. Choi, N. S. Lee, D. S. Chung, J. H. Kang, I. T. Han, J. M. Kim, M. H. Moon, and J. S. Kim, Proc. Mater. Res. Soc. Symp. 593 (2000).

54. S. Bandow, A. M. Rao, K. A. Williams, A. Thess, R. E. Smalley, and P. C. Eklund, J. Phys. Chem. B 101, 8839 (1997)? C C I

55. A. G. Rinzler, J. Liu, H. Dai, P. Nikolaev, C. B. Huffman, F. J Rodriguez-Macais, P. J. Boul, A. H. Lu, D. Heymann, D. T. Colbert, R. S. Lee, J. E. Fischer, A. M. Rao, P. C. Eklund, and R. E. Smalley, Appl. Phys. A 67, 29 (1998).

56. C. Xu, E. Flahaut, S. R. Bailey, G. Brown, J. Sloan, K. S. Coleman, V. C. Williams, and M. L. H. Green, Chem. Res. Chinese Univ. 18, 130 (2002).

57. L. P. Biro, N. Q. Khanh, Z. Vertesy, Z. E. Horvath, Z. Osvath, A. Koos, J. Gyulai, A. Kocsonya, Z. Konya, X. B. Zhang, G. V. Tendeloo, A. Fonseca, and J. B. Nagy, Mater. Sci. Eng. C C19, 9 (2002).

58. E. Dujardin, T. W. Ebbesen, A. Krishnan, and M. M. J. Treacy, Adv. Mater. 10, 611 (1998).

59. K. B. Shelimov, R. O. Esenaliev, A. G. Rinzler, C. B. Huffman, and R. E. Smalley, Chem. Phys. Lett. 282, 429 (1998).

60. A. R. Harutyunyan, B. K. Pradhan, J. Chang, G. Chen, and P. C. Eklund, J. Phys. Chem. B 106, 8671 (2002).

61. C. J. Ko, C. Y. Lee, F. H. Ko, H. L. Chen, and T. C. Chu, Microelectron. Eng. 73-74, 570 (2004).

62. S. Arepalli, P. Nikolaev, O. Gorelik, V. G. Hadjiev, W. Holmes, B. S. Files, and L. Yowell, Carbon 42, 1783 (2004).

63. A. Srivastava, O. N. Srivastava, S. Talapatra, R. Vajtai, and P. M. Ajayan, Nature 3, 610 (2004).

64. R. Saito, M. Fujita, G. Dresselhaus, and M. S. Dresselhaus, Appl. Phys. Lett. 60, 2204 (1992).
65. R. H. Baughman, A. A. Zakhidov, and W. A. de Heer, Science 297 , 787 (2002).

66. M. Terrones, Ann. Rev. Mater. Res. 33, 419 (2003).

67. M. S. Dresselhaus, P. C. Eklund, and R. Saito, Phys. World 33 (1998).

68. S. G. Louie, in Topics in Applied Physics, edited by M. S. Dresselhaus, G. Dresselhaus, and P. Avouris, Springer, New York (2001), Vol. 80, p. 113.

69. R. S. Ruoff, D. Qian, and W. K. Liu, C. R. Physique 4, 993 (2003)

70. S. Amelinckx, D. Bernaerts, X. B. Zhang, G. van Tendeloo, and J. van Landuyt, Science 267, 1334 (1995).

71. S. Banerjee, T. H. Benny, and S. S. Wong, J. Nanosci. Nanotechnol. 5, 841 (2005).

72. W. Liang, M. Bockrath, D. Bozovic, J. H. Hafner, M. Tinkham, and H. Park, Nature 411, 665 (2001).

73. C. Berger, P. Poncharal, Y. Yi, and W. de Heer, J. Nanosci. Nanotechnol. 3, 171 (2003).

74. B. Q. Wei, R. Vajtai, and P. M. Ajayan, Appl. Phys. Lett. 79, 1172 (2001).

75. N. Koratkar, A. Modi, E. Lass, and P. M. Ajayan, J. Nanosci. Nanotechnol. 4, 744 (2004).

76. G. U. Sumanasekera, C. K. W. Adu, S. Fang, and P. C. Eklund, AtPhys. Rev. Lett. 85, 1096 (2000).

77. P. Lambin, J. P. Vigneron, A. Fonseca, J. B. Nagy, and A. A. Lucas, Synth. Met. 77, 249 (1996).

78. L. Chico, V. H. Crespi, L. X. Benedict, S. G. Louie, and M. L. Cohen, Phys. Rev. Lett. 76, 971 (1996).

79. A. Rochefort, D. R. Salahub, and P. Avouris, Chem. Phys. Lett. 297, 45 (1998).

80. D. Danailov, P. Keblinski, S. Nayak, and P. M. Ajayan, J. Nanosci. Nanotechnol. 2, 503 (2002).

81. C. Y. Wang, C. Q. Ru, and A. Mioduchowski, J. Nanosci. Nanotechnol. 3, 199 (2003).

82. A. Rochefort, P. Avouris, F. Lesage, and D. R. Salahub, Phys. Rev. B 60, 13824 (1999).

83. M. Kociak, A. Y. Kasimov, S. Gueron, B. Reulet, I. I. Khodos, Y. B. Gorbatov, V. T. Volkov, L. Vaccarini, and H. Bouchiat, Phys. Rev. Lett. 86, 2416 (2001).

84. J. Zhaoa and R. H. Xieb, J. Nanosci. Nanotechnol. 3, 459 (2003).

85. N. Koratkar, A. Modi, J. Kim, B. Q. Wei, R. Vajtai, S. Talapatra, and P. M. Ajayan, J. Nanosci. Nanotechnol. 4, 69 (2004).

86. M. M. J. Treacy, T. W. Ebbesen, and J. M. Gibson, Nature 381, 678 (1996).

87. E. W. Wong, P. E. Sheehan, and C. M. Lieber, Science 277, 1971 (1997).

88. M. R. Falvo, G. J. Clary, R. M. Taylor, V. Chi, F. P. Brooks, S. Washburn, and R. Superfine, Nature 389, 582 (1997).

89. J. Gaillard, M. Skove, and A. M. Rao, Appl. Phys. Lett. 86, 233109 (2005).

90. O. Lourie and H. D. Wagner, J. Mater. Res. 13, 2418 (1998).

91. M. F. Yu, B. S. Files, S. Arepalli, and R. S. Ruoff, Phys. Rev. Lett. 84, 5552 (2000).

92. M. F. Yu, O. Lourie, M. J. Dyer, K. Moloni, T. F. Kelly, and R. S. Ruoff, Science 287, 637 (2000).

93. P. Jaroenapibal, D. E. Luzzi, S. Evoy, and S. Arepalli, Appl. Phys. Lett. 85, 4328 (2004).

94. O. Lourie, D. M. Cox, and H. D. Wagner, Phys. Rev. Lett. 81, 1638 (1998).

95. P. H. Zhang, P. E. Lammert, and V. H. Crespi, Phys. Rev. Lett. 81, 5346 (1998).

96. T. Belytschko, S. P. Xiao, G. C. Schartz, and R. S. Ruoff, Phys. Rev. B 65, 235430 (2002).

97. J. P. Salvetat, J. M. Bonard, N. H. Thomson, A. J. Kulik, L. Forro, W. Benoit, and L. Zuppiroli, Appl. Phys. A 69, 255 (1999).

98. M. B. Nardelli, B. I. Yakobson, and J. Bernholc, Phys. Rev. B 57, R4277 (1998). 
99. M. C. Weisenberger, E. A. Grulke, D. Jacques, A. T. Rantell, and R. Andrewsa, J. Nanosci. Nanotechnol. 3, 535 (2003).

100. H. Miyagawa, M. Misra, and A. K. Mohanty, J. Nanosci. Nanotechnol. 5, 1593 (2005).

101. J. Suhr, N. Koratkar, P. Keblinski, and P. M. Ajayan, Nature 4, 134 (2005).

102. J. Hone, M. C. Llaguno, N. M. Nemes, A. T. Johnson, J. E. Fischer, D. A. Walters, M. J. Casavant, J. Schmidt, and R. E. Smalley, Appl. Phys. Lett. 77, 666 (2000).

103. W. Yi, L. Lu, D. L. Zhang, Z. W. Pan, and S. S. Xie, Phys. Rev. B 59, R9015 (1999).

104. A. Mizel, L. X. Benedict, M. L. Cohen, S. G. Louie, A. Zettl, N. K. Budraa, and W. P. Beyermann, Phys. Rev. B 60, 3264 (1999).

105. J. C. Lasjaunias, K. Biljakoviae, Z. Benes, J. E. Fischer, and P. Monceau, Phys. Rev. B 65, 113409 (2002).

106. J. Hone, M. Whitney, C. Piskoti, and A. Zettl, Phys. Rev. B 59, R2514 (1999).

107. P. Kim, L. Shi, A. Majumdar, and P. L. McEuen, Phys. Rev. Lett. 87, 215502 (2001).

108. W. Zhang, Z. Zhu, F. Wang, T. Wang, L. Sun, and Z. Wang, Nanotechnology 15, 936 (2004).

109. J. Liu and H. Dai [Online]. Available: http://www.nnf.cornell.edu/ 2002re u/ Liu. pdf (2002).

110. P. Dharap, Z. Li, S. Nagarajaiah, and E. V. Barrera, Nanotechnology 15,379 (2004).

111. J. Wu, J. Zang, B. Larade, H. Guo, X. G. Xong, and F. Liu, Phys. Rev. B 69, 153406 (2004).

112. S. Sotiropoulou and N. A. Chaniotakis, Anal. Bioanal. Chem. 375 , $103(\mathbf{2 0 0 3})$

113. S. Ghosh, A. K. Sood, and N. Kumar, Science 299, 1042 (2003).

114. J. Kong, N. R. Franklin, C. Zhou, M. G. Chapline, S. Peng, K. Cho, and H. Dai, Science 287, 622 (2000).

115. A. Modi, N. Koratkar, E. Lass, B. Wei, and P. M. Ajayan, Nature 424, 171 (2003).

116. E. S. Snow, F. K. Perkins, E. J. Houser, S. C. Badescu, and T. L. Reinecke, Science 307, 1942 (2005).

117. Y. T. Jang, S. I. Moon, J. H. Ahn, Y. H. Lee, and B. K. Ju, Sens. Actuators B 99, 118 (2004).

118. M. Penza, F. Antolini, and M. A. Vittori, Sens. Actuators B 100, 47 (2004).

119. K. G. Ong, K. Zeng, and C. A. Grimes, IEEE Sens. J. 2, 82 (2002).

120. K. S. V. Santhanam, R. Sangoi, and L. Fuller, Sens. Actuators $B$ 106, 766 (2005).

121. V. T. S. Wong and W. J. Li, Proc. IEEE Int. Symp. Circuits Sys. 4 IV844 (2003).

122. P. W. Barone, S. Baik, D. A. Heller, and M. S. Strano, Nature 4, 86 (2005).

123. C. Y. Li and T. W. Chou, Nanotechnology 15, 1493 (2004).

124. R. K. Roy, M. P. Chowdhury, and A. K. Pal, Vacuum 77, 223 (2005).

125. C. K. M. Fung, V. T. S. Wong, R. H. M. Chan, and W. J. Li, IEEE Trans. Nanotechnol. 3, 395 (2004).

126. R. Mateiu, Z. J. Davis, D. N. Madsen, K. Molhave, P. Boggild, A. M. Rassmusen, M. Brorson, C. J. H. Jacobsen, and A. Boisen, Microelectron. Eng. 73-74, 670 (2004).

127. P. Liu, L. Dong, T. Fukuda, F. Arai, M. Nagai, and Y. Imaizumi, Proc. Int. Conf. Intel. Mechatr. Automat. 12 (2004).

128. Q. Zhao, M. D. Frogley, and H. D. Wagner, Polym. Adv. Technol. 13, 759 (2002).

129. Y. Li, M. J. Yang, and Y. Chen, J. Mater. Sci. 40, 245 (2005).

130. M. Penza, F. Antolini, and M. A. Vittori, Thin Solid Films 472, 246 (2005).

131. M. Penza, M. A. Tagliente, P. Aversa, and G. Cassano, Chem. Phys. Lett. 409, 349 (2005)

132. I. Sayago, E. Terrado, E. Lafuente, M. C. Horrillo, W. K. Maser, A. M. Benito, R. Navarro, E. P. Urriolabeitia, M. T. Martinez, and J. Gutierrez, Synth. Met. 148, 15 (2005).
133. G. Boas, Biophot. Int. 12, 57 (2005).

134. L. Liu and Y. Zhang, Sens. Actuators A 116, 394 (2004).

135. S. G. Wang, Q. Zhang, R. Wang, and S. F. Yoon, Biochem. Biophys. Res. Commun. 311, 572 (2003).

136. S. Chopra, A. Pham, J. Gaillard, A. Parker, and A. M. Rao, Appl. Phys. Lett. 80, 4632 (2002).

137. F. Picaud, R. Langlet, M. Arab, M. Devel, C. Girardet, S. Natarajan, S. Chopra, and A. M. Rao, J. Appl. Phys. 97, 114316 (2005).

138. H. T. Ng, A. Fang, J. Li, and S. F. Y. Lia, J. Nanosci. Nanotechnol. 1, 375 (2001).

139. P. Young, Y. Lu, R. Terrill, and J. Li, J. Nanosci. Nanotechnol. 5, 1509 (2005).

140. B. Perez, M. Pumera, M. del Valle, A. Merkoci, and S. Alegret, J. Nanosci. Nanotechnol. 5, 1694 (2005).

141. T. Someya, J. Small, P. Kim, C. Nuckolls, and J. T. Yardley, Nano Lett. 3, 877 (2003).

142. Y. Lin, F. Lu, Y. Tu, and Z. Ren, Nano Lett. 4, 191 (2004).

143. Q. Zhao, M. B. Nardelli, W. Lu, and J. Bernholc, Nano Lett. 5, 847 (2005).

144. C. Staii, A. T. Johnson, M. Chen, and A. Gelperin, Nano Lett. 5, 1774 (2005).

145. H. M. So, K. Won, Y. H. Kim, B. K. Kim, B. H. Ryu, P. S. Na, H. Kim, and J. O. Lee, J. Am. Chem. Soc. 127, 11906 (2005).

146. J. Wang and M. Musameh, Anal. Chem. 75, 2075 (2003).

147. L. B. da Silva, S. B. Fagan, and R. Mota, Nano Lett. 4, 65 (2004).

148. Q. Fu and J. Liu, J. Phys. Chem. B 109, 13406 (2005).

149. J. Wang, M. Musameh, and Y. Lin, J. Am. Chem. Soc. 125, 2408 (2003).

150. J. Li, Y. Lu, Q. Ye, M. Cinke, J. Han, and M. Meyyappan, Nano Lett. 3, 929 (2003).

151. M. Zhang and W. Gorski, Anal. Chem. 77, 3960 (2005).

152. P. Qi, O. Vermesh, M. Grecu, A. Javey, Q. Wang, H. Dai, S. Peng, and K. J. Cho, Nano Lett. 3, 347 (2003).

153. E. Bekyarova, M. Davis, T. Burch, M. E. Itkis, B. Zhao, S. Sunshine, and R. C. Haddon, J. Phys. Chem. B 108, 19717 (2004).

154. C. Li, M. Curreli, H. Lin, B. Lei, F. N. Ishikawa, R. Datar, R. J. Cote, M. E. Thompson, and C. Zhou, J. Am. Chem. Soc. 127, 12484 (2005).

155. M. Penza, G. Cassano, P. Aversa, F. Antolini, A. Cusano, M. Consales, M. Giordano, and L. Nicolais, Sens. Actuators B 111112, 171 (2005).

156. W. J. Guan, Y. Li, Y. Q. Chen, X. B. Zhang, and G. Q. Hu, Biosens. Bioelect. 21, 508 (2005).

157. Y. Zhang, K. Yu, R. Xu, D. Jiang, L. Luo, and Z. Zhu, Sens. Actuators A 120, 142 (2005).

158. F. Qu, M. Yang, J. Jiang, G. Shen, and R. Yu, Anal. Biochem. 344, 108 (2005).

159. J. Suehiro, G. Zhou, and M. Hara, Sens. Actuators B 105, 164 (2005).

160. R. P. Deo, J. Wang, I. Block, A. Mulchandani, K. A. Joshi, M. Trojanowicz, F. Scholz, W. Chen, and Y. Liu, Anal. Chim. Acta 530, 185 (2005).

161. M. Lucci, P. Regoliosi, A. Reale, A. D. Carlo, S. Orlanducci, E. Tamburri, M. L. Terranova, P. Lugli, C. D. Natale, A. D'Amico, and R. Paolesse, Sens. Actuators B 111-112, 181 (2005).

162. S. Takeda, A. Sbagyo, Y. Sakoda, A. Ishii, M. Sawamura, K. Sueoka, H. Kida, K. Mukasa, and K. Mutsumoto, Biosens. Bioelectron. 21, 201 (2005).

163. J. Suehiro, G. Zhou, H. Imakiire, W. Ding, and M. Hara, Sens. Actuators B 108, 398 (2005).

164. G. Li, J. M. Liao, G. Q. Hu, N. Z. Ma, and P. J. Wu, Biosens. Bioelect. 20, 2140 (2005).

165. Y. X. Liang, Y. J. Chen, and J. H. Wang, Appl. Phys. Lett. 85, 666 (2004).

166. J. Chung, K. H. Lee, J. Lee, D. Troya, and G. C. Schatz, Nanotechnology 15, 1596 (2004) 
167. M. Shim, N. W. S. Kam, R. J. Chen, Y. Li, and H. Dai, Nano Lett. 2, 285 (2002).

168. M. Zhang, A. Smith, and W. Gorski, Anal. Chem. 76, 5045 (2004).

169. S. Hrapovic, Y. Liu, K. B. Male, and J. H. T. Luong, Anal. Chem. 76, 1083 (2004).

170. Z. Li, P. Dharap, S. Nagarajaiah, E. V. Barrera, and J. D. Kim, Adv. Mater. 16, 640 (2004).

171. J. Wang, G. Liu, and M. R. Jan, J. Am. Chem. Soc. 126, 3010 (2004).

172. P. He and L. Dai, Chem. Commun. 3, 348 (2004).

173. B. Philip, J. K. Abraham, A. Chandrasedhar, and V. K. Varadan, Smart Mater. Struct. 12, 935 (2003).

174. S. Chopra, K. McGuire, N. Gothard, and A. M. Rao, Appl. Phys. Lett. 83, 2280 (2003).

175. O. K. Varghese, P. D. Kichambre, D. Gong, K. G. Ong, E. C. Dickey, and C. A. Grimes, Sens. Actuators B 81, 32 (2001).

176. L. Valentini, C. Cantalini, I. Armentano, J. M. Kenny, L. Lozzi, and S. Santucci, Diam. Rel. Mater. 13, 1301 (2004).

177. Y. M. Wong, W. P. Kang, J. L. Davidson, A. Wisitsora-at, and K. L. Soh, Sens. Actuators B 93, 327 (2003).

178. P. M. Ajayan and O. Zhou, in Topics in Applied Physics, edited by M. S. Dresselhaus, G. Dresselhaus, and P. Avouris, Springer, New York (2001), Vol. 80, p. 391.

University

179. W. A. de Heer, MRS Bulletin: Adv. Carbon Nanotubes 29, 281 (2004).

180. E. Bekyarova, Y. Ni, E. B. Malarkey, V. Montana, J. L. McWilliams, R. C. Haddon, and V. Parpura, J. Biomed. Nanotechnol. 1, 3 (2005).

181. N. Sinha and J. T. W. Yeow, IEEE Trans. Nanobioscience 4, 180 (2005).

182. A. Bhargava [Online]. Available: http://www.ewh.ieee.org/r10/ Bombay/news3/page4.html (1999).

183. R. Caldwell, H. Dai, Q. Wang, and R. Grow [Online]. Available: http://www.nnf.cornell.edu/2002re u/Caldwell. pdf (2002).

184. M. C. Shults, R. K. Rhodes, S. J. Updike, B. J. Gilligan, and W. N. Reining, IEEE Trans. Biomed. Eng. 41, 937 (1994).

185. A. Bolz, V. Lang, B. Merkely, and M. Schaldach, Proc. Ann. Int. Conf. IEEE Eng. Med. Biol. 5, 2341 (1997).

186. R. Shandas and C. Lanning, Med. Biol. Eng. Comp. 41, 416 (2003)

187. N. Gordon and U. Sagman [Online], http://www.regenerativemedicine.ca/nanomed/Nanomedicine\%20Taxonomy\%20(Feb\%202003). PDF (2003).

188. O. P. Galaasen [Online]. Available: http://plausible.custompublish com/cparticle54173-5911.html, Med. Technol. (2002).

189. P. Adrian [Online] Available: http://www.sensorsmag.com/ resources/businessdigest/sbd 0703. shtml, Sens. Bus. Dig. (2003).
190. M. Romero, R. Figueroa, and C. Madden [Online]. Available: http://www.devicelink.com/mddi/archive/00/10/004.html, Med. Dev. Diag. Ind. Mag. (2000).

191. H. Joseph, B. Swafford, and S. Terry, Sens. Mag. 14, 47 (1997).

192. K. Sakai, J. Chem. Eng. Jpn. 30, 587 (1997).

193. T. R. Hsu, MEMS and Microsystems: Design and Manufacture, McGraw-Hill, Boston (2002)

194. M. H. Westbrook and J. D. Turner, Automotive Sensors, Institute of Physics Publishing, Philadelphia (1994).

195. H. Weinberg [Online]. Available: http://www.sensorsmag.com/ articles/0202/36/, Sens. Online (2002).

196. D. Ivnitski, I. Abdel-Hamid, P. Atanasov, E. Wilkins, and S. Stricker, Electroanalysis 12, 317 (2000).

197. J. H. T. Luong, S. Hrapovic, and D. Wang, Electroanalysis 17, 47 (2005).

198. N. Funazaki, A. Hemmi, S. Ito, Y. Asano, Y. Yano, N. Miura, and N. Yamazoe, Sens. Actuators B 25, 797 (1995).

199. T. Vo-Dinh, 1st Int. Symp. Micro and Nano Technol., Honolulu, Hawaii (2004), p. 1.

200. G. Chiti, G. Marrazza, and M. Mascini, Anal. Chim. Acta 427, 155 (2001).

201. Z. Xu, X. Chen, X. Qu, J. Jia, and S. Dong, Biosen. Bioelectron. 20, 579 (2004).

202. R. G. Wright, L. V. Kirkland, M. Zgol, D. Adebimpe, and R. Mulligan, Tech. Proc. NSTI Nano. Conf. Trade Show 3, 244 (2004).

203. M. Cinke, J. Li, B. Chen, A. Cassell, L. Delzeit, J. Han, and M. Meyyappan, Chem. Phys. Lett. 365, 69 (2002).

204. S. M. Cho, Y. J. Kim, Y. S. Kim, Y. Yang, and S. C. Ha, Proc. IEEE Sens. 701 (2004).

205. L. Liu and Y. Zhang, Sens. Actuators A 116, 394 (2004).

206. M. Penza, G. Cassano, P. Aversa, F. Antolini, A. Cusano, A. Cutolo, M. Giordano, and L. Nicolais, Appl. Phys. Lett. 85, 2379 (2004).

207. M. S. Dresselhaus and H. Dai, MRS Bulletin: Adv. Carbon Nanotubes 29, 237 (2004).

208. Y. Wang, M. J. Kim, H. Shan, C. Kittrell, H. Fan, L. M. Ericson, W. F. Hwang, S. Arepalli, R. H. Hague, and R. E. Smalley, Nano Lett. 5, 997 (2005).

209. R. F. Service, Science 300, 243 (2003).

210. R. F. Service, Science 304, 1732 (2004).

211. C. W. Larn, J. T. James, R. McCluskey, and R. L. Hunter, Toxicol. Sci. 77,126 (2004).

212. A. A. Shvedova, V. Castranova, E. R. Kisin, D. Schwegler-Berry, A. R. Murray, V. Z. Gandelsman, A. Maynard, and P. Baron, J. Toxicol. Environ. Health A 66, 1909 (2003).

Received: 21 September 2005. Accepted: 12 October 2005. 